NASA/TM-2003-212533

\title{
Test Rig for Evaluating Active Turbine Blade Tip Clearance Control Concepts
}

Scott B. Lattime

Ohio Aerospace Institute, Brook Park, Ohio

Bruce M. Steinetz

Glenn Research Center, Cleveland, Ohio

Malcolm G. Robbie

Analex Corporation, Brook Park, Ohio 
Since its founding, NASA has been dedicated to the advancement of aeronautics and space science. The NASA Scientific and Technical Information (STI) Program Office plays a key part in helping NASA maintain this important role.

The NASA STI Program Office is operated by Langley Research Center, the Lead Center for NASA's scientific and technical information. The NASA STI Program Office provides access to the NASA STI Database, the largest collection of aeronautical and space science STI in the world. The Program Office is also NASA's institutional mechanism for disseminating the results of its research and development activities. These results are published by NASA in the NASA STI Report Series, which includes the following report types:

- $\quad$ TECHNICAL PUBLICATION. Reports of completed research or a major significant phase of research that present the results of NASA programs and include extensive data or theoretical analysis. Includes compilations of significant scientific and technical data and information deemed to be of continuing reference value. NASA's counterpart of peerreviewed formal professional papers but has less stringent limitations on manuscript length and extent of graphic presentations.

- TECHNICAL MEMORANDUM. Scientific and technical findings that are preliminary or of specialized interest, e.g., quick release reports, working papers, and bibliographies that contain minimal annotation. Does not contain extensive analysis.

- CONTRACTOR REPORT. Scientific and technical findings by NASA-sponsored contractors and grantees.
- CONFERENCE PUBLICATION. Collected papers from scientific and technical conferences, symposia, seminars, or other meetings sponsored or cosponsored by NASA.

- SPECIAL PUBLICATION. Scientific, technical, or historical information from NASA programs, projects, and missions, often concerned with subjects having substantial public interest.

- TECHNICAL TRANSLATION. Englishlanguage translations of foreign scientific and technical material pertinent to NASA's mission.

Specialized services that complement the STI Program Office's diverse offerings include creating custom thesauri, building customized databases, organizing and publishing research results ... even providing videos.

For more information about the NASA STI Program Office, see the following:

- Access the NASA STI Program Home Page at http://www.sti.nasa.gov

- E-mail your question via the Internet to help@sti.nasa.gov

- Fax your question to the NASA Access Help Desk at 301-621-0134

- Telephone the NASA Access Help Desk at 301-621-0390

- Write to:

NASA Access Help Desk

NASA Center for AeroSpace Information 7121 Standard Drive

Hanover, MD 21076 
NASA/TM-2003-212533

Test Rig for Evaluating Active Turbine Blade Tip Clearance Control Concepts

Scott B. Lattime

Ohio Aerospace Institute, Brook Park, Ohio

Bruce M. Steinetz

Glenn Research Center, Cleveland, Ohio

Malcolm G. Robbie

Analex Corporation, Brook Park, Ohio

Prepared for the

39th Joint Propulsion Conference and Exhibit

cosponsored by AIAA, ASME, SAE, and ASEE

Huntsville, Alabama, July 20-23, 2003

National Aeronautics and

Space Administration

Glenn Research Center 


\section{Acknowledgments}

The authors recognize Mr. Arthur H. Erker and Mr. Michael Hoychick, Analex Corporation; and Mr. Richard A. Tashjian, QSS Group, Inc., for their efforts and support in the design and the detailing of the ACC system and test rig. The authors also acknowledge the NASA Glenn Revolutionary Aeropropulsion Concepts

(RAC) Project for supporting this research.

The Propulsion and Power Program at

NASA Glenn Research Center sponsored this work.

Available from

NASA Center for Aerospace Information 7121 Standard Drive

Hanover, MD 21076
National Technical Information Service 5285 Port Royal Road

Springfield, VA 22100

Available electronically at http:/ /gltrs.grc.nasa.gov 


\title{
TEST RIG FOR EVALUATING ACTIVE TURBINE BLADE TIP CLEARANCE CONTROL CONCEPTS
}

\author{
Scott B. Lattime* \\ Ohio Aerospace Institute \\ Brook Park, Ohio 44142 \\ Bruce M. Steinetz ${ }^{\dagger}$ \\ National Aeronautics and Space Administration \\ Glenn Research Center \\ Cleveland, Ohio 44135 \\ Malcolm G. Robbie \\ Analex Corporation \\ Brook Park, Ohio 44142
}

\begin{abstract}
Improved blade tip sealing in the high pressure compressor and high pressure turbine can provide dramatic improvements in specific fuel consumption, time-on-wing, compressor stall margin and engine efficiency as well as increased payload and mission range capabilities of both military and commercial gas turbine engines. The design of a first generation mechanically actuated active clearance control system for turbine blade tip clearance management is presented along with the design of a bench top test rig in which the system is to be evaluated. The active clearance control system utilizes mechanically actuated seal carrier segments and clearance measurement feedback to provide fast and precise active clearance control throughout engine operation. The purpose of this active clearance control system is to improve upon current case cooling methods. These systems have relatively slow response and do not use clearance measurement, thereby forcing cold build clearances to set the minimum clearances at extreme operating conditions (e.g., takeoff, re-burst) and not allowing cruise clearances to be minimized due to the possibility of throttle transients (e.g., step change in altitude).
\end{abstract}

The active turbine blade tip clearance control system design presented herein will be evaluated to ensure that proper response and positional accuracy is achievable under simulated high-pressure turbine conditions. The test rig will simulate proper seal carrier pressure and temperature loading as well as the magnitudes and rates of blade tip clearance changes of an actual gas turbine

*Senior Research Associate, Member AIAA.

${ }^{\dagger}$ Senior Research Engineer, Associate Fellow AIAA. engine. The results of these evaluations will be presented in future works.

\section{INTRODUCTION}

Gas path sealing continues to be an important component in regards to improving turbine engine efficiency and operation. Blade tip sealing has remained a challenging problem since the development of the gas turbine engine. Environmental conditions at the tip seal location include gas temperatures up to $2500^{\circ} \mathrm{F}$, surface speeds up to $1500-\mathrm{fps}$ as well as unburned jet fuel and contaminants (dirt, sand, etc.) that make for very challenging surroundings for a controllable seal design. In addition to the extreme operating environment, is the fact that these conditions change due to engine operation and environmental conditions outside the engine, which in turn, act to vary the clearance between the rotating blade tips and the surrounding static casing (shroud).

Improved blade tip sealing in both the high pressure compressor (HPC) and high pressure turbine (HPT) can provide dramatic improvements in specific fuel consumption (SFC), compressor stall margin and engine efficiency as well as increased payload and mission range capabilities. Improved clearance management, especially in the HPT, can dramatically improve engine service life or time-on-wing (TOW). Maintenance costs for major overhauls of today's large commercial gas turbine engines can easily exceed \$1M.

\section{$\underline{\text { Background }}$}

Figure 1 shows the HPT blade tip seal location in a modern gas turbine engine. ${ }^{1}$ The figure shows a cross section of the combustor and two-stage 


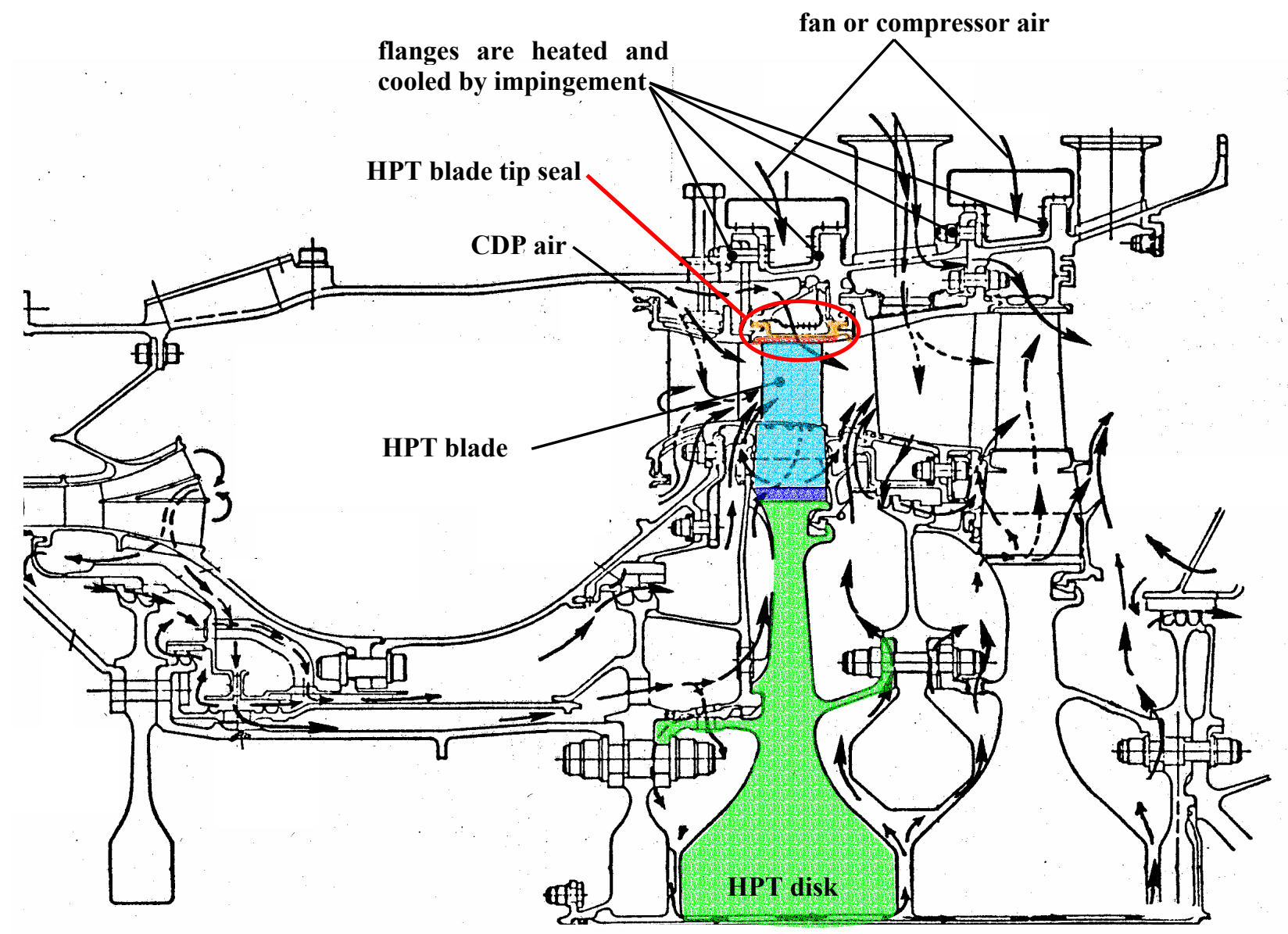

Figure 1: HPT blade tip seal location in a modern gas turbine engine ${ }^{1}$

HPT. The turbine disk, blade, and tip seal of the firststage turbine are labeled. Blade tip or outer air seals line the inside of the stationary case forming a shroud around the rotating blades, limiting the gas that spills over the tips. Blade tip clearance varies over the operating points of the engine (e.g., ground idle, takeoff, cruise, decel, etc.) as well as over the cycle life of the engine. These clearance variations are due to a number of loads on both static and rotating parts and wear of these parts.

Load mechanisms can be separated into two categories, namely engine (power-induced) loads and flight loads. Engine loads include centrifugal, thermal, internal engine pressure, and thrust loads. Flight loads include inertial (gravitational), aerodynamic (external pressure), and gyroscopic loads. Engine loads can produce both axisymmetric and asymmetric clearance changes (see Figures 2 and 3). Flight loads produce asymmetric clearance changes. Load mechanisms generally act to temporarily alter blade tip clearance, while wear mechanisms permanently change tip clearance.
Wear mechanisms of blade tip seals can be generally separated into two categories, namely, rubbing (blade incursion), and erosion. Blade rubs and erosion are expected to occur throughout the service life of an engine. Engine build clearances are in fact sometimes chosen to operate line-to-line at extreme operating conditions (e.g., takeoff, re-accel). In this case, manufacturers set cold-build clearances such that during the engine green-state ("run-in") the blades will lightly rub the seal shrouds thereby achieving tight clearances and mitigating the effects of manufacturing tolerance stack-up. Rubs can also contribute to accelerating the effects of both erosion and thermal fatigue by wearing protective coatings (e.g., thermal barrier coatings) or distorting cooling passages of the blade tips during an incursion event.

Lattime and Steinetz provided a comprehensive review on the mechanisms of tip clearance variation, their effects in gas turbine engines, methods of controlling tip clearance and the benefits associated with reducing tip clearance ${ }^{2}$. A review of some of the benefits of reduced tip clearance is presented here. 


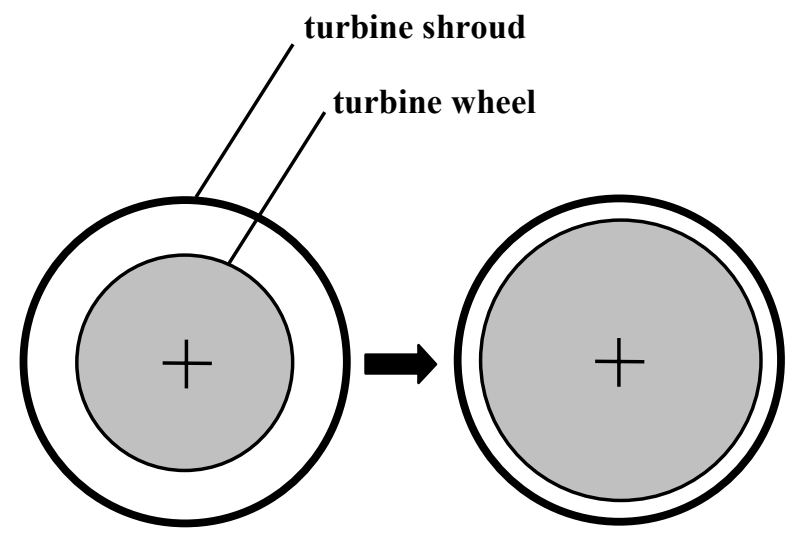

Figure 2: Axisymmetric clearance change

Blade tip clearance directly influences gas turbine performance, efficiency, and life. Reducing air leakage over the blade tips increases turbine efficiency and permits the engine to meet performance and thrust goals with less fuel burn and lower rotor inlet temperatures. Running the turbine at lower temperatures increases the cycle life of hot section components, which in turn, increases engine service life (TOW) by increasing the time between overhauls.

\section{$\underline{\text { Fuel Savings }}$}

Engine SFC and exhaust gas temperature (EGT) are directly related to HPT blade tip clearances. Wiseman et al., indicate that for every 0.001-in. increase in HPT tip clearance, SFC increases approximately $0.1 \%$, while EGT increases $1{ }^{\circ} \mathrm{C}{ }^{3} \quad$ Thus, a 0.010 -in. HPT tip clearance decrease would roughly produce a $1 \%$ decrease in SFC and a $10^{\circ} \mathrm{C}$ decrease in EGT. Military engines generally show slightly greater HPT tip clearance influence on SFC and EGT due to their higher operating speeds and temperatures over large commercial engines. Improvements of this magnitude would produce huge savings in annual fuel and engine maintenance costs. Lattime and Steinetz projected cost savings for U.S. carrier's fuel usage of over $\$ 160 \mathrm{M}$ for the year 2003 alone due only to a modest $1 \%$ reduction in SFC, based on 2001 average fuel prices. ${ }^{2}$

\section{$\underline{\text { Reduced Emissions }}$}

Reducing fuel consumption also reduces aero engine total emissions. The Rocky Mountain Institute estimates that Americans alone now fly 764 million trips per year (2.85 airline trips per person). ${ }^{4}$ The energy used by commercial aircraft has nearly doubled over the last three decades. The increased fuel consumption accounts for $13 \%$ of the total transportation sector emissions of carbon dioxide $\left(\mathrm{CO}_{2}\right)$. Modern aero engine emissions are made up of over $71 \% \mathrm{CO}_{2}$ with about $28 \%$ water $\left(\mathrm{H}_{2} \mathrm{O}\right)$ and $0.3 \%$

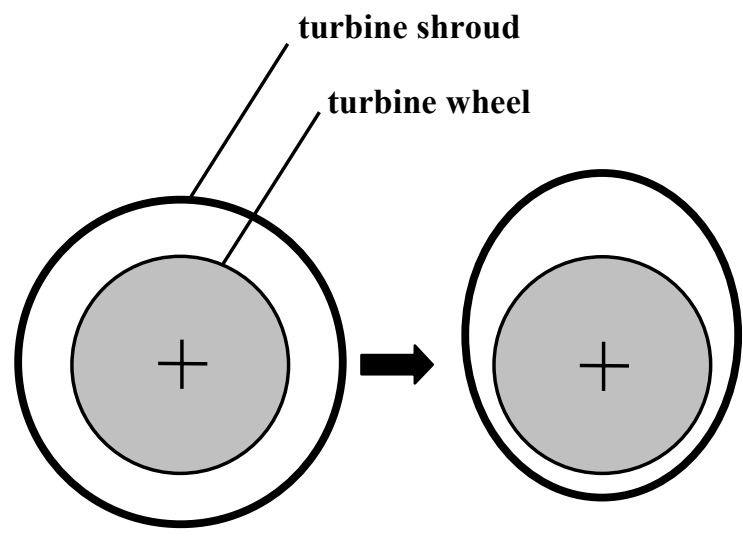

Figure 3: Asymmetric clearance change

nitrogen oxide $\left(\mathrm{NO}_{2}\right)$ along with trace amounts of carbon monoxide $(\mathrm{CO})$, sulfur dioxide $\left(\mathrm{SO}_{2}\right)$, etc. Air transport accounts for $2.5 \%$ (600 million tones) of the world's $\mathrm{CO}_{2}$ production. ${ }^{5}$ Clearly a reduction in fuel burn will significantly reduce aero engine emissions.

\section{Extended Service Life}

Current large commercial engines have life cycles (time between overhauls) that vary significantly (e.g., 3,000 to 10,000 cycles). Their cycle lives are basically determined by how long they retain a positive EGT margin. New engines or newly overhauled engines are shipped with a certain cold build clearance. This clearance increases with time due primarily to rubs early in the engine's life. ${ }^{6}$ Martin reported a $1 \%$ loss estimate in engine performance due to clearance changes that occurs during the production flight test acceptance profile. ${ }^{7}$ As the engine operating clearances increase, the engine must work harder (hotter) to produce the same work and is therefore less efficient. This increase in operating temperature, particularly takeoff EGT, further promotes the degradation of hot section components due to thermal fatigue. Retaining engine takeoff EGT margin by maintaining tight tip clearances and either eliminating rubs or compensating for them can dramatically increase engine cycle life. This would lead to considerable savings in engine maintenance costs over a period of years due to the significant costs of engine overhauls.

\section{Objectives}

This work is part of a larger research effort to develop viable mechanical concepts for active clearance control (ACC) systems for use in the HPT section of large commercial aircraft to improve upon the case-cooling methods employed today. The objective of this work is to present the development of a test rig for the evaluation of ACC system concepts that are currently being developed at the NASA Glenn Research Center. 
The design of a first generation mechanical ACC system that utilizes independent hydraulic actuators will be presented in conjunction with the test rig design. The test rig will be used to analyze the ability of various actuator concepts to control the positioning of a segmented shroud seal support structure under properly simulated HPT temperature and pressure conditions with the required system response rate and accuracy.

\section{RIG DESIGN OVERVIEW}

Designing a system to manage blade tip clearance is not a new topic. As Lattime and Steinetz reported in their review on clearance control systems, well over one hundred patents exist in the United States alone pertaining to blade tip clearance control. ${ }^{2}$ However, the authors have found virtually no published experimental results for these patented systems. The authors of this work have focused their efforts on designing mechanical ACC systems that articulate the seal shroud via mechanical linkages connected to actuators that reside outside the extreme environment of the HPT. The authors opted for this style of design due to a lack of high temperature/low profile actuators that are presently available and the fact that the system is to function in a large, commercial, axial-flow HPT. Radial compressor and turbine designs may find less risk in an ACC system that functions in the axial direction along the rotor shaft. Obviously, penetration through the case requires secondary seals, but the authors felt this tradeoff to be a more viable alternative than designing an actuation system that functions inside the HPT case. Leakage levels for the secondary seals have been determined to be small, as will be discussed in a later section of this work.

The rig design was focused on simulating the environment surrounding the backsides of the seal segments. As such, the design was concentrated on simulating the temperature and pressure conditions that exist on the backsides of the seal segments, without the need for a rotating turbine. This greatly simplified the rig design. The authors plan to assess the response of the ACC system to the effects of a turbine wheel (i.e., rapid clearance closures due to mechanical and thermal loads) by simulating closures electronically, as will be discussed in a later section.

\section{$\underline{\text { Rig Specifications }}$}

Specifications for the rig were chosen to closely simulate the environment (temperature and pressure) and operating requirements (displacement rate and magnitude) of large commercial engines.

\section{Temperature and Pressure}

The backside of the HPT shroud (blade outer-air-seal) is generally cooled with compressor discharge air $\left(\mathrm{T}_{3}\right.$ air: 1200 to $1300^{\circ} \mathrm{F}$ ). This cooling is necessary for the shroud segments to survive the $2500^{\circ} \mathrm{F}$ and higher rotor inlet gas temperatures. The cooling air is also used to purge the leading and trailing edges of the shroud segments, providing a positive backflow margin from the hot rotor inlet flow. This cooling flow is shown in Figure 4 for the first stage shroud of a two-stage HPT. The pressures surrounding the shroud segment can be expressed as a function of the compressor discharge pressure $\left(\mathrm{CDP} ; \mathrm{P}_{3}\right)$. Flow path pressure adjacent to the HPT shroud varies axially due to the work extracted by the turbine blades. For large commercial engines, the pressure of the cooling air behind the shroud is about 60 to $80 \%$ of $\mathrm{P}_{3}$. Pressure in the tip clearance region varies axially from the leading to the trailing edge of the shroud about 70 to $30 \%$ of $\mathrm{P}_{3}$, respectively. To maintain a positive backflow margin from the rotor inlet air, the cooling pressure on the backside of the shroud must always be higher than the rotor inlet side. The radial pressure difference across the shroud creates a load inward to the shaft centerline. A resultant moment also exists on the shroud that is created by the non-uniform axial pressure distribution. $\mathrm{P}_{3}$ is highest during maximum thrust events such as takeoff and re-accel. For large commercial engines this translates to a maximum cooling air pressure differential of up to 150psi across the shroud. Test rig components were designed to accommodate the above temperature and pressure magnitudes. However, the test rig will not simulate an axially varying pressure distribution across the seal carriers.

\section{Actuation Range and Rate}

The largest HPT tip clearance variations, as discussed by Lattime and Steinetz, are due to centrifugal growth of the rotor during takeoff and re-accel conditions. ${ }^{2}$ Maximum tip clearance changes due to axisymmetric and asymmetric loads on the rotor and stator components are on the order of 0.050-in. The Federal Aviation Administration (FAA) requires that gas turbine engines have the ability to reach $95 \%$ rated takeoff power from ground idle (or from 15\% rated takeoff power) in 5.0 seconds. $^{8}$ In general, this requirement sets a limiting case of maximum displacement and minimum response time for actuation systems to be used as ACC. Assuming a maximum clearance change of 0.050 -in., this would require actuation systems that can provide radial clearance change on the order of 0.010 -in./s. These response rates 


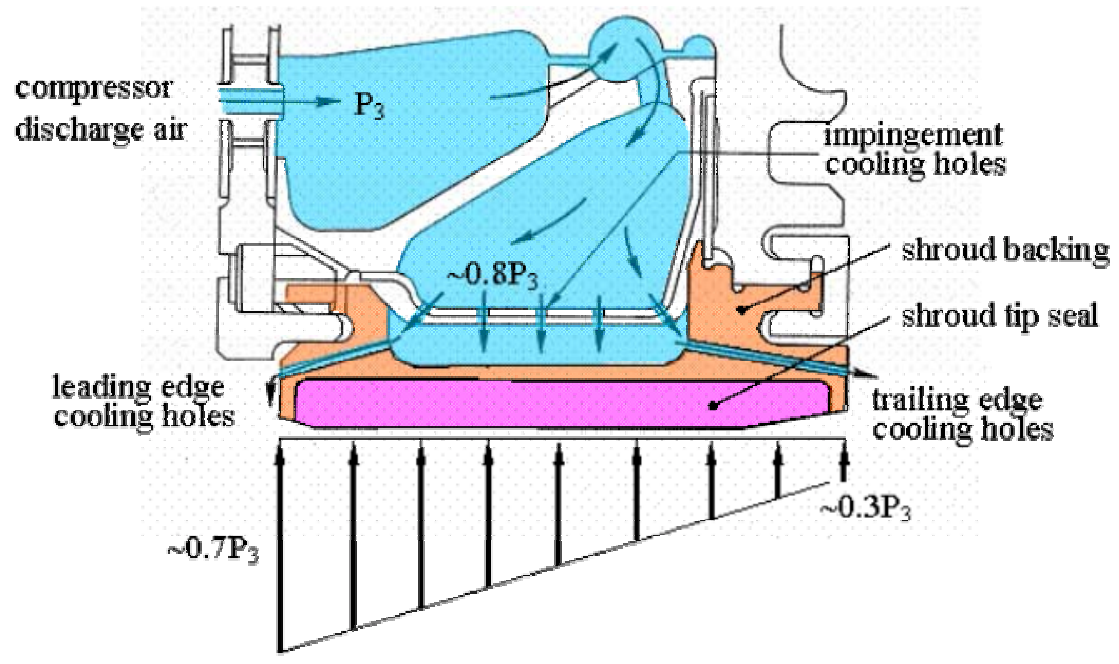

Figure 4: Axial pressure distribution across HPT blade tip seal cross section

exclude faster dynamic clearance changes (i.e., once per revolution events), which is beyond the scope of this effort.

\section{Rig Design Criteria: Creep Life}

The substantial diameter of the segmented shroud structure ( 20-in.), even under moderate pressures ( $\sim 120$-psi), gives rise to significant loads, and hence stresses, to which the actuation system and components must react. These stresses coupled with high temperatures $\left(1200\right.$ to $\left.1300^{\circ} \mathrm{F}\right)$ can significantly reduce component cycle life due to creep. Managing these stresses with adequate materials and geometry to improve component cycle life was a driving factor in the rig component design. The authors utilized LarsonMiller parameter data for a variety of high temperature, super alloys to design components to achieve a desired minimum cycle life.

The Larson-Miller theory correlates the results of shortterm elevated temperature material performance testing to long-term performance at more moderate temperatures. For each combination of material and stress level, the Larson-Miller theory relates a unique value of a parameter $\mathrm{P}$ to temperature and creep life by: ${ }^{9}$

$$
\mathrm{P}=\mathrm{T}(\mathrm{C}+\log \mathrm{t})
$$

Thus, for a specified creep life and temperature, a properly suited material and maximum stress can be graphically determined provided the Larson-Miller parameter data exists. The authors chose Inconel 718 as the material for most of the hot section components. These components were designed for less than $0.5 \%$ creep strain, resulting in a 15 -ksi limiting stress. This stress level corresponds to over 100,000 hours life at $1300{ }^{\circ} \mathrm{F}$ and approximately 300 hours life at $1500^{\circ} \mathrm{F}$.

\section{TEST RIG AND SUPPORT SYSTEMS}

The test rig housing and main components are shown in Figures 5 through 7 . Figure 5 shows the outside of the housing, while Figures 6 and 7 show the inside of the housing and the major components of the rig. The test rig comprises six main components: the housing, the radiant heater, the pressurized chamber, the seal carrier assembly, the actuator rod assemblies, and the hydraulic actuators.

At the heart of the rig is a segmented shroud structure (seal carrier) that would structurally support the tip seal shroud segments in the engine. Radial movement of the seal carriers controls the effective position/diameter of the seal shroud segments, thereby controlling blade tip clearance. The carrier segments are connected to independent hydraulic actuators through an actuator rod assembly as shown in Figures 6 and 7. The foot of the actuator rod assembly positions the carrier segments in the radial direction, while allowing relative circumferential movement or dilation of the seal carrier segments through a pinned and slotted arrangement as shown in Figures 7 and 8.

The rig housing consists of two concentric cylinders, which form an annular cavity. An annular radiant heater made of upper and lower halves surrounds the segmented seal carrier structure to simulate the HPT tip seal backside temperature environment. A pressurized chamber encloses the carrier segments inside the annular heater through which heated pressurized air is supplied to simulate the $\mathrm{P}_{3}$ cooling/purge air pressure on the seal backsides. Heated air enters the chamber 


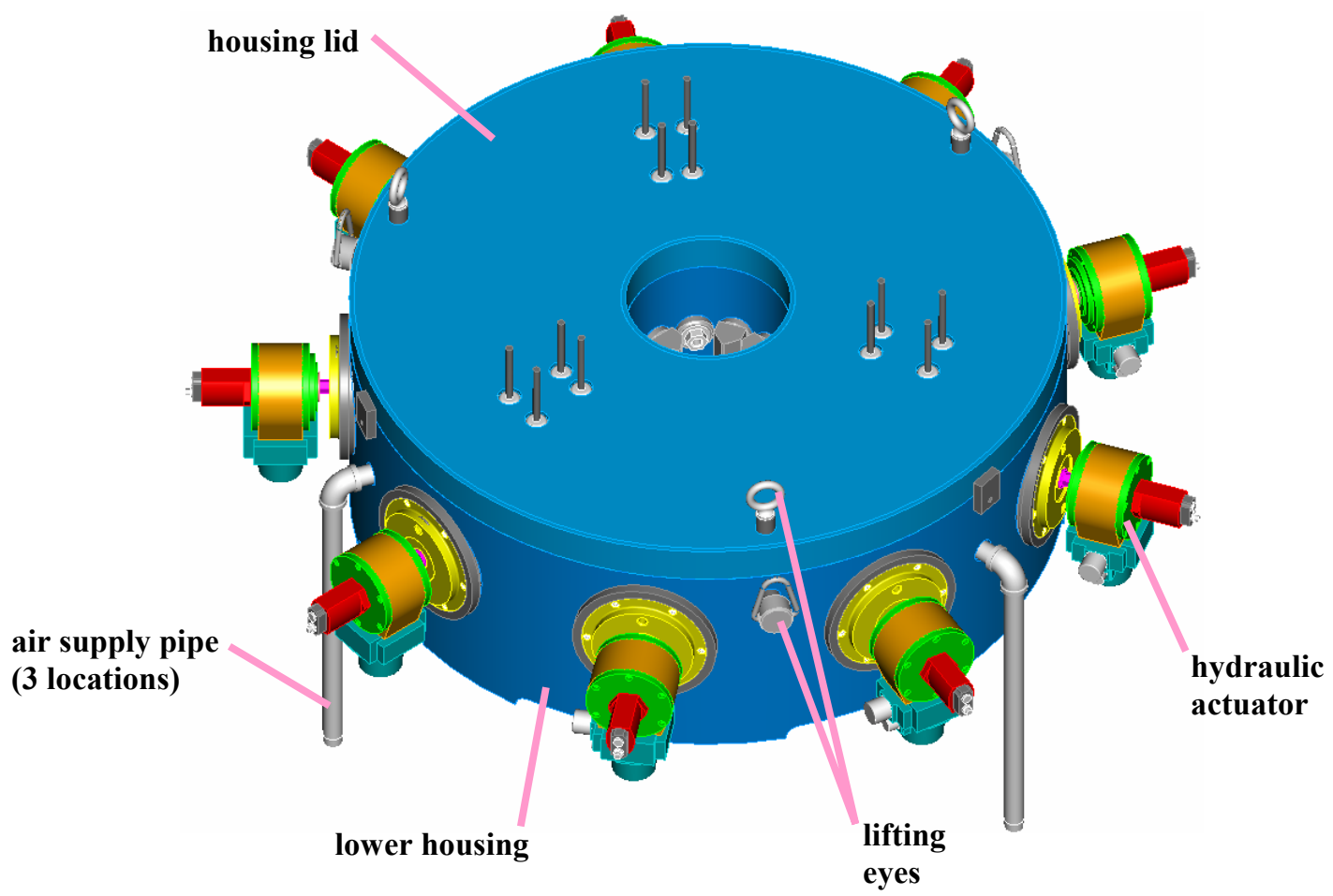

Figure 5: ACC Test Rig

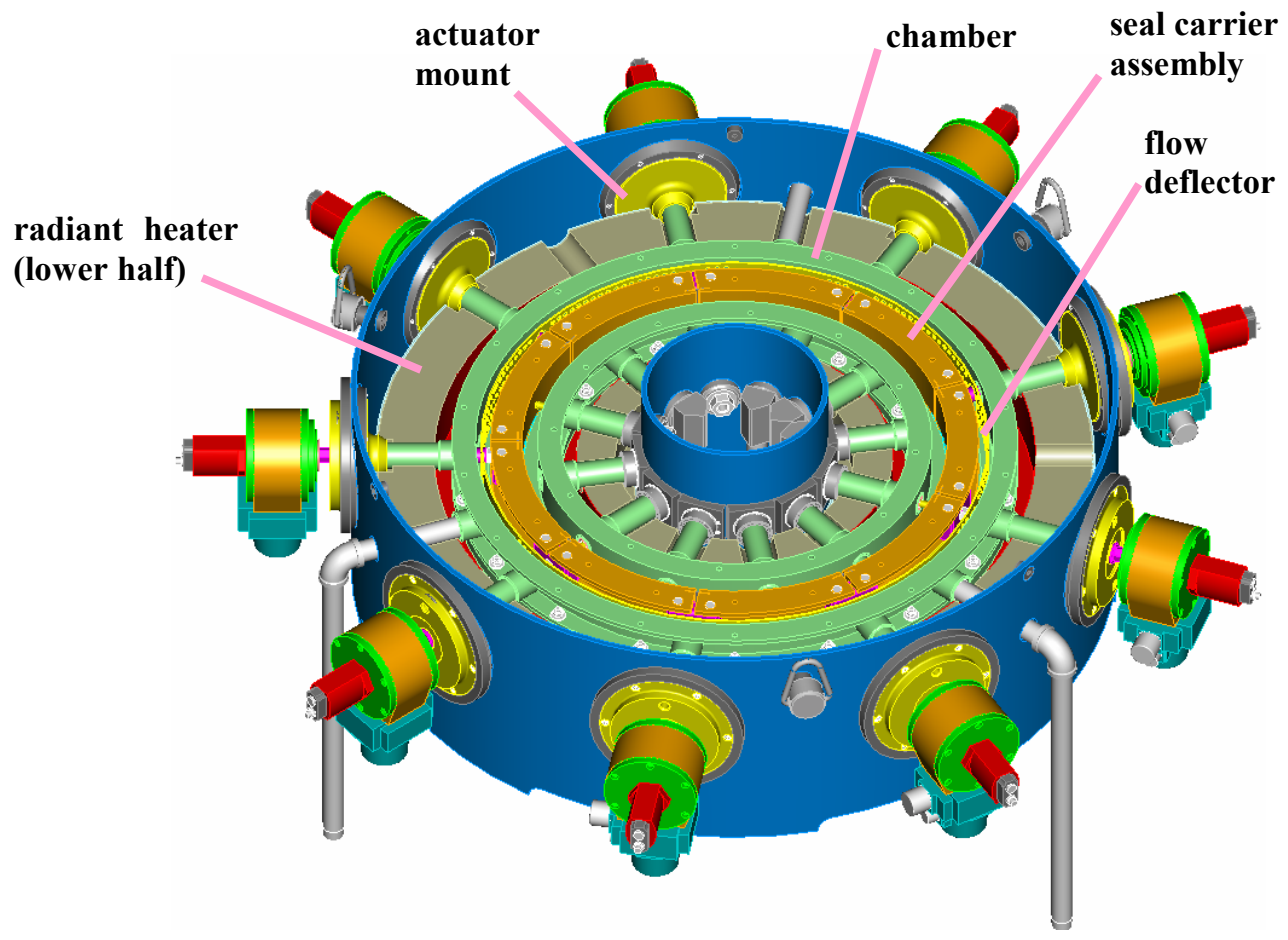

Figure 6: ACC Test Rig with Housing Lid and Chamber Cover Plate Removed 


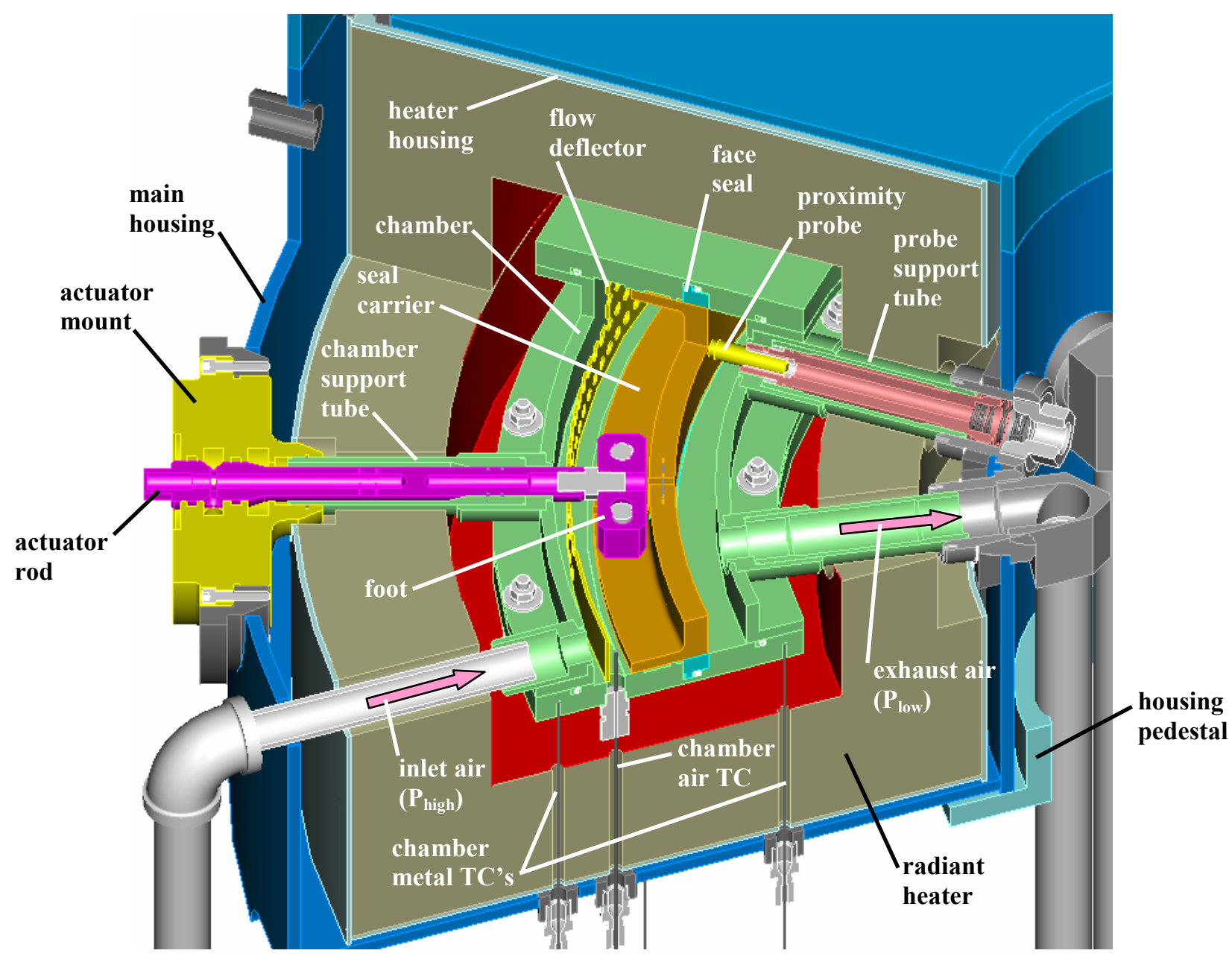

Figure 7: Rig Cutaway Detail

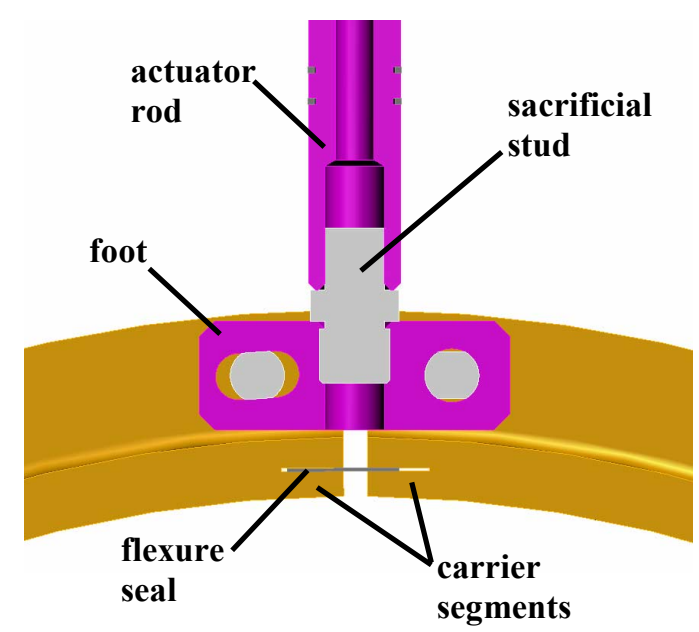

Figure 8: Actuator Rod Foot-Carrier Detail

via three pipes that are fed from a manifold at the air heater exhaust through radial inlet ports as shown in Figures 6 and 7. The flow is directed circumferentially around the outer chamber wall by a flow deflector that has a series of radial holes positioned about its circumference except at the inlet positions. Air that escapes over and between the carrier segments is vented out of the rig through a number of exhaust pipes that protrude radially along the inner chamber wall. The number and inner diameter of exhaust pipes were chosen to eliminate the possibility of backpressure at the exhaust ports. The pressurized air is sealed along the sides of the seal carrier segments by contacting face seals that are energized via metal "E"-seals imbedded in the upper and lower chamber plates. The joints between adjoining carrier segments are sealed with thin metal flexures. A series of radial tubes projecting outward from the chamber's inner and outer side walls serve as supports, air supply and exhaust ports, probe fixtures, and the actuator rod guides. The chamber functions to support and align the carrier segments and actuator rods, as well as to house instrumentation and to seal the pressurized air from the radiant heater which is not designed to carry any pressure loading. 
High temperature proximity probes measure the radial displacement of the seal carriers at various circumferential locations. These measurements provide direct feedback control to the independent actuators and allow the desired radial position (clearance) to be set. The direct feedback control system allows for simulation of realistic transient tip clearance changes in lieu of a rotating turbine wheel. Superimposing a mission-clearance-profile over the actual clearance measurement input to the actuator controllers will allow researchers to assess the system's response to the most dramatic transient events such as mechanical and thermal loading of the rotor during takeoff and re-accel.

\section{$\underline{\text { Seal Carrier Design }}$}

The seal carrier assembly is made of nine segments that are joined together by pinned connections to the actuator rod feet. Figure 9 shows two of these segments assembled with an actuator rod. These structures not only support the seal segments that would exist in an actual engine, but they must also support the cooling/purge air pressure load that exists along the seal carrier backside as well as the pin reaction loads at the carrier's ends. These loads occur inside the chamber at the highest temperatures. The carriers must also provide for secondary sealing along the chamber upper and lower lid structures as well as between the carrier's own joint ends. In doing so, the carriers must maintain their shape to prevent non-uniform circumferential clearance distribution (out-of-roundness) of the seal segments.

The nine carrier segments are made of Inconel 718 . This material was selected for its high temperature strength and creep properties and is widely used for turbine engine hot section components. The carriers have a "U"-shape cross section to provide a rigid structure with reduced mass. They have an inner radius of 10.25-in., a width of 2.0-in., and span about $40^{\circ}$. The side flanges are 0.25 -in. thick. The sections of these parts have been over-designed to prevent displacement due to pressure and thermal loading. The authors recognize that the carrier segments, as well as other components, will need to be optimized to reduce weight for actual engine applications. Selecting optimal section designs is left for future exercises.

\section{Actuator Rod Assembly}

The actuator rod assembly is shown in Figures 7, 8, and 9. The assembly is made of three major components, namely: the actuator rod, the sacrificial stud, and the foot, all made of Inconel 718. The actuator rod assembly functions as the link between the carrier segments and the actuators. Because the carrier segments are always pressure loaded, the rods and actuator load trains remain in tension. This mitigates backlash effects on positional accuracy. The rods act to position the carriers in the radial and circumferential directions and are supported by the chamber support tubes.

The actuator rods have an enlarged diameter on the end that bears against the actuator mount. Tight radial clearances $(0.0015$-in.) at this location serve to align the actuator rods. Towards the foot-end of the actuator rod is a series of metal piston ring seals. The ring seals act to seal the chamber air as well as to provide a bearing surface against the support tubes for alignment. The actuator rod is connected to the foot through a stud to provide a sacrificial part in case the connecting threads bind due to oxidation, preventing disassembly of the rod and foot. A high temperature solid lubricant will be used on the threads to help prevent binding.

\section{$\underline{\text { Seal Carrier Movement }}$}

Because the carriers are constrained by a pinned connection at one end and a slotted connection at the other, the segments must shift circumferentially as they are displaced in the radial direction. The slots in the feet are cut on a tangent to the radius on which the carrier pinholes are located. This keeps the carrier segments from cocking (the ends of the carrier segment are kept at the same radius) while it is displaced in both the radial and circumferential directions. The circumferential length of the carrier segments as well as the length of the slot in the actuator rod foot allows a radial displacement of 0.2 -in. for each of the nine segments. The slots for the flexure seals have adequate clearance to prevent the segments from becoming archbound as the segments are moved radially inward.

The pins are made of Inconel X750. This material was chosen for its high strength and creep resistance at high temperatures as well as its wear resistance to other nickel-based alloys. ${ }^{10}$ In particular, the material was selected to help minimize galling against adjacent Inconel 718 components. The pins have flats machined on the diameter that contacts the slots. This provides a bearing surface and lowers the contact stress developed between the pin and foot. The pins are designed with a slip-fit for ease of assembly.

\section{Actuator Rod Thermal Design}

Figure 10 shows the results of a thermal analysis on the rig assembly with the chamber temperature of $1500^{\circ} \mathrm{F}$. The model contained the stainless steel housing, the ceramic fiber radiant heater, and the Inconel 718 chamber and actuator rod assembly. All component surfaces inside the radiant heater (including the radiant heater surface) were set to $1500^{\circ} \mathrm{F}$. A convection 


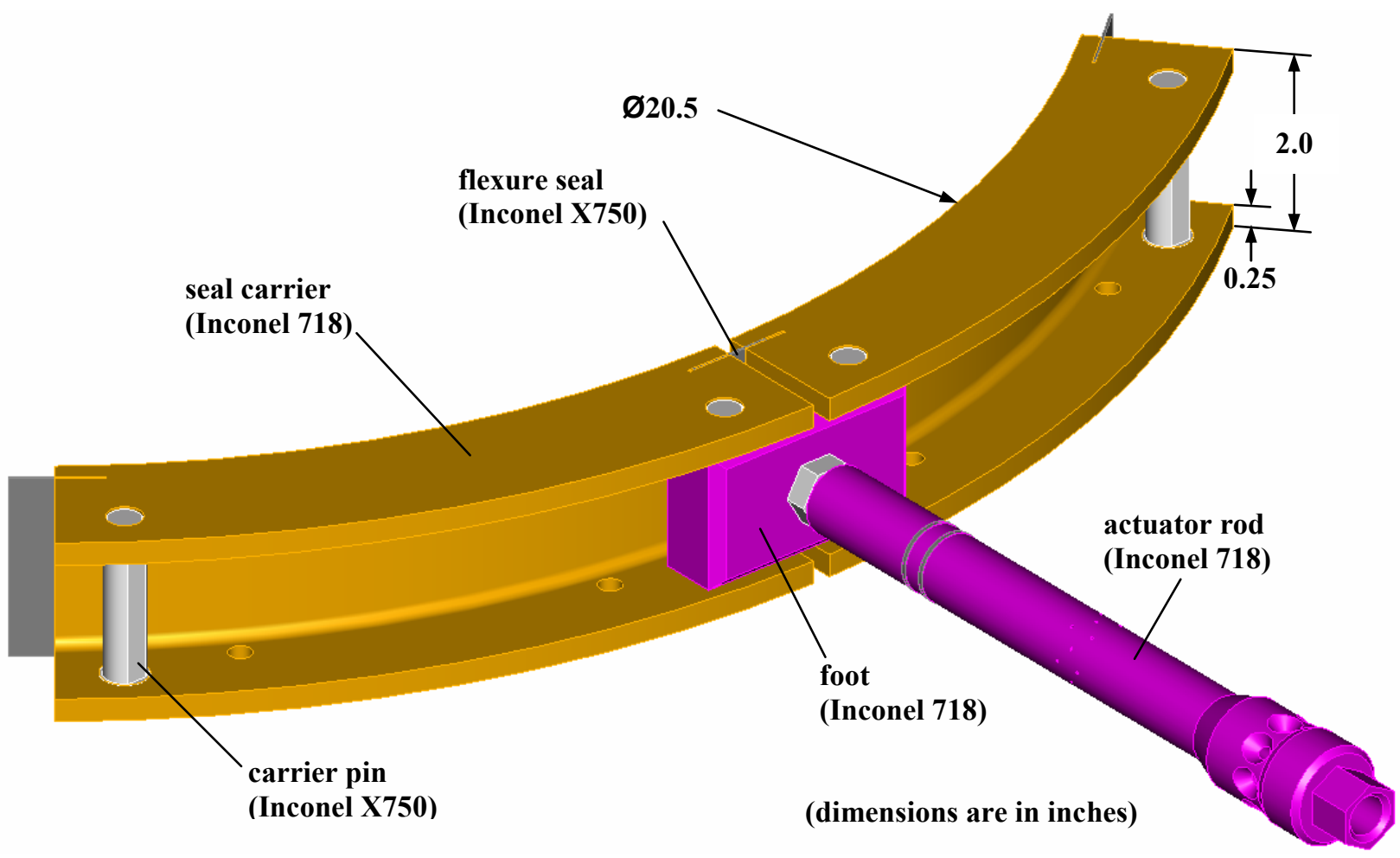

Figure 9: Seal Carrier and Actuator Rod Assembly
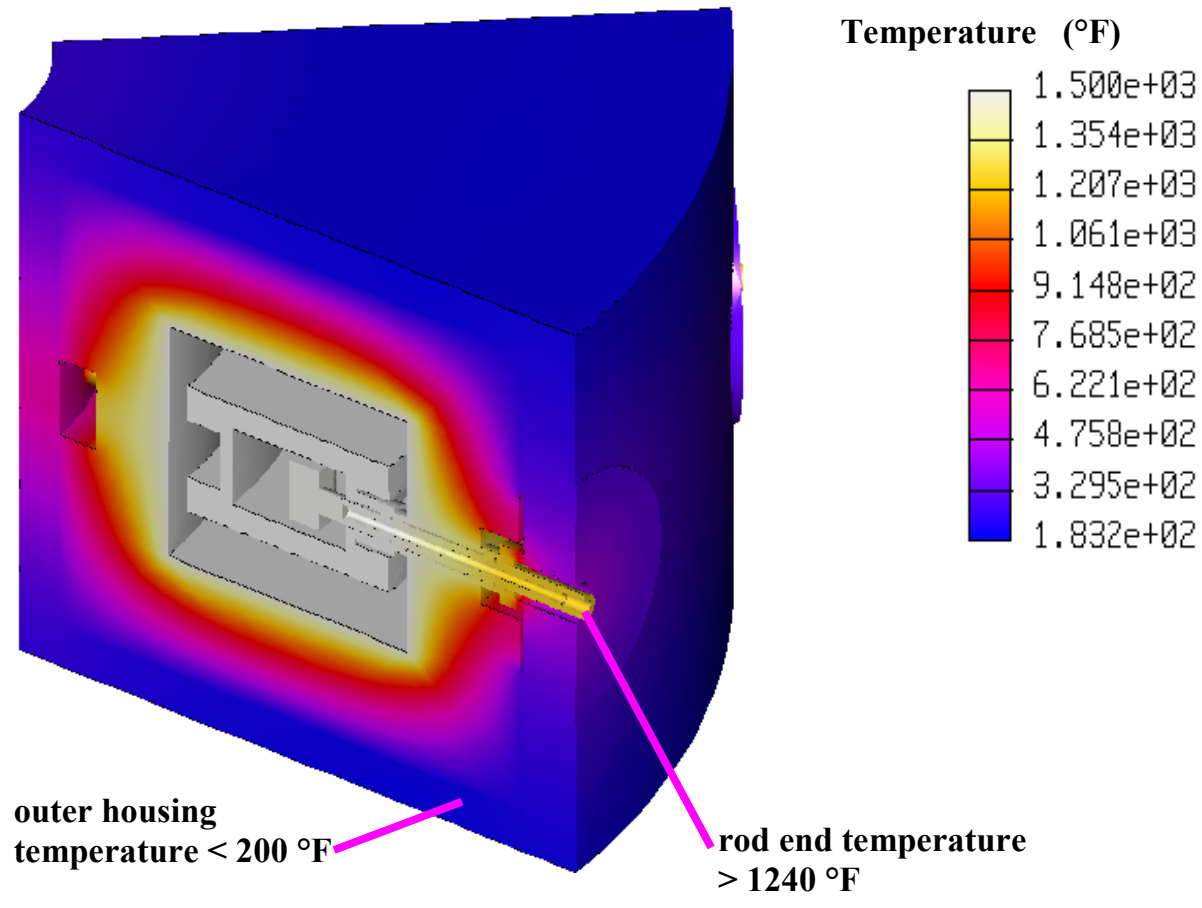

Figure 10: Assembly Thermal Analysis (no rod cooling) 
coefficient of $4.4-\mathrm{Btu} / \mathrm{ft}^{2}-\mathrm{hr}-{ }^{\circ} \mathrm{F}$ was applied to the outer housing surfaces representing free convection of air at ambient conditions. A steady-state thermal analysis estimated the rod-end temperature at $1240^{\circ} \mathrm{F}$. This rod-end temperature greatly exceeds the upper operating temperature $\left(\sim 250^{\circ} \mathrm{F}\right)$ allowed by conventional hydraulic actuators. A cooling scheme for the rod end was then designed to allow the use of conventional actuators. The cooling scheme, shown in Figure 11, allows the actuator rod and support tube to function as a tube-in-tube heat exchanger using a small flow rate of ambient $\left(70^{\circ} \mathrm{F}\right)$ air to cool the assembly.

\section{Heat Transfer Analyses}

The authors performed a simple one-dimensional heat transfer analysis to determine feasibility of the cooling scheme by bounding the required flow rate. In this analysis, the heat conducted down the slender actuator rod (equation 2) is balanced by the heat that is carried away by the cooling air (equation 3 ). ${ }^{11}$

$$
\begin{aligned}
& \mathrm{q}_{\text {cond }}=\frac{\mathrm{kA}}{\mathrm{L}\left(\mathrm{T}_{\mathrm{h}}-\mathrm{T}_{\mathrm{c}}\right)} \\
& \mathrm{q}_{\text {conv }}=\dot{\mathrm{m}} \mathrm{p}_{\mathrm{p}}\left(\mathrm{T}_{\mathrm{o}}-\mathrm{T}_{\mathrm{i}}\right)
\end{aligned}
$$

Based on the low flow rates that were calculated, the authors implemented the features of the cooling scheme to the rod assembly shown in Figure 11. The cooling holes were made from three sets of six, 0.03-in. diameter holes drilled around the circumference of the hollow rod. Ambient air, supplied at the rod end through features in the actuator mount, travels axially through the center of the rod, passes radially through the cooling holes, and exits between the support tube and outer diameter of the rod.

\section{Experimental Validation}

A mockup of the cooled actuator rod design was built to validate the calculations (Figure 12). A solid steel block (simulating the actuator foot) was bolted to one end of a stainless steel tube (simulating the rod). Another larger tube was welded to the block (simulating the support tube) in a concentric arrangement. An air supply line was attached to the end of the inner tube from which the assembly was supported and inserted into a box furnace as shown in Figure 12. The insulation thickness of the furnace closely approximated that of the radiant heater designed for the rig. A plastic supply line was used minimize heat loss through the supply tube. Thermocouples were attached to measure the temperatures of the mass, the end of the inner rod, and the end of the outer tube. The furnace was heated to $1500^{\circ} \mathrm{F}$ and after the mass temperature stabilized at $1500^{\circ} \mathrm{F}$, ambient air at approximately $70^{\circ} \mathrm{F}$ was supplied to the assembly. Figure 13 shows the results of the furnace test. Temperatures of the furnace, mass, tube end, and rod end are shown as a function of time on the left vertical axis. The cooling air volumetric flow is shown on the right vertical axis. The chart shows that for minimal air flow (3.0 to $4.0-\mathrm{scfm})$ both the tube and rod end temperatures were kept below $250{ }^{\circ} \mathrm{F}$. Thus the cooling scheme design was successfully validated and implemented into the rig design to allow the use of conventional actuators. Careful attention was paid to this cooled actuator rod design to lay the groundwork for an approach scalable to an engine application.

\section{Actuator Rod Stress Analysis}

The chamber pressure on the outer surfaces of the carriers creates a tensile load on the actuator rods. Additional tensile loading comes from the frictional drag of the face seals that contact the sides of carrier segments. The actuator rods were sized to handle a 3000-lbf tensile load due to the chamber pressure, face seal drag, and a 1.5 factor of safety. Because one end of the rod operates in the high temperature zone, the thin sections of the hollow rod where the piston ring seals are seated were a concern for stress concentration. A structural analysis on the rod design under a 3000-lbf tensile load at $1500^{\circ} \mathrm{F}$ showed that the stresses were kept well below the maximum of 15 -kpsi to ensure a minimum life of 300 hours at these maximum conditions.

\section{Chamber Design}

The chamber assembly, shown in Figure 14, serves as a pressure vessel, support, and alignment structure for the carrier-actuator rod assembly. In doing so, it is the most critical static structure of the entire rig. The Inconel 718 chamber is formed from two bands that make up the sides of a rectangular annulus and two rims that form the upper and lower cover plates. The bands are formed from two, 0.375-in. thick, rectangular plates that are rolled and welded at their respective ends. The annulus formed from this assembly has an outer diameter of 25-in., inner diameter of 19-in., and a height of 2-in. The upper and lower cover plates are fixed to the side walls via stud and nut assemblies (Inconel 718). The studs are used for ease of disassembly in case the stud threads bind with their nuts due to oxidation. The same compound used on the actuator rod assembly will be utilized to prevent binding of the fasteners due to thermal cycling.

Figure 15 shows a detailed view of the chamber cross section. Aside from a number of metallic seals that will 


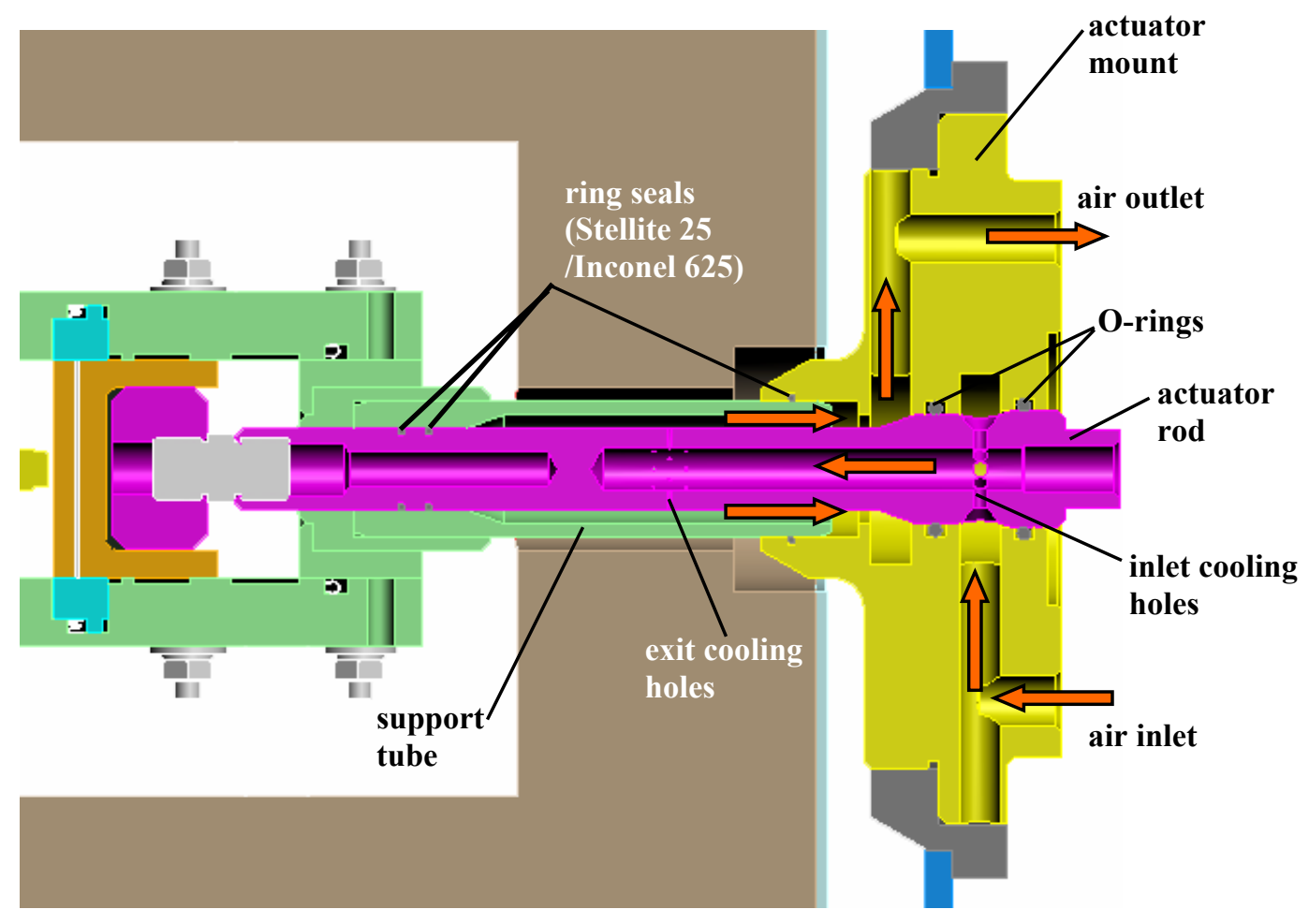

Figure 11: Cooled Actuator Rod Design
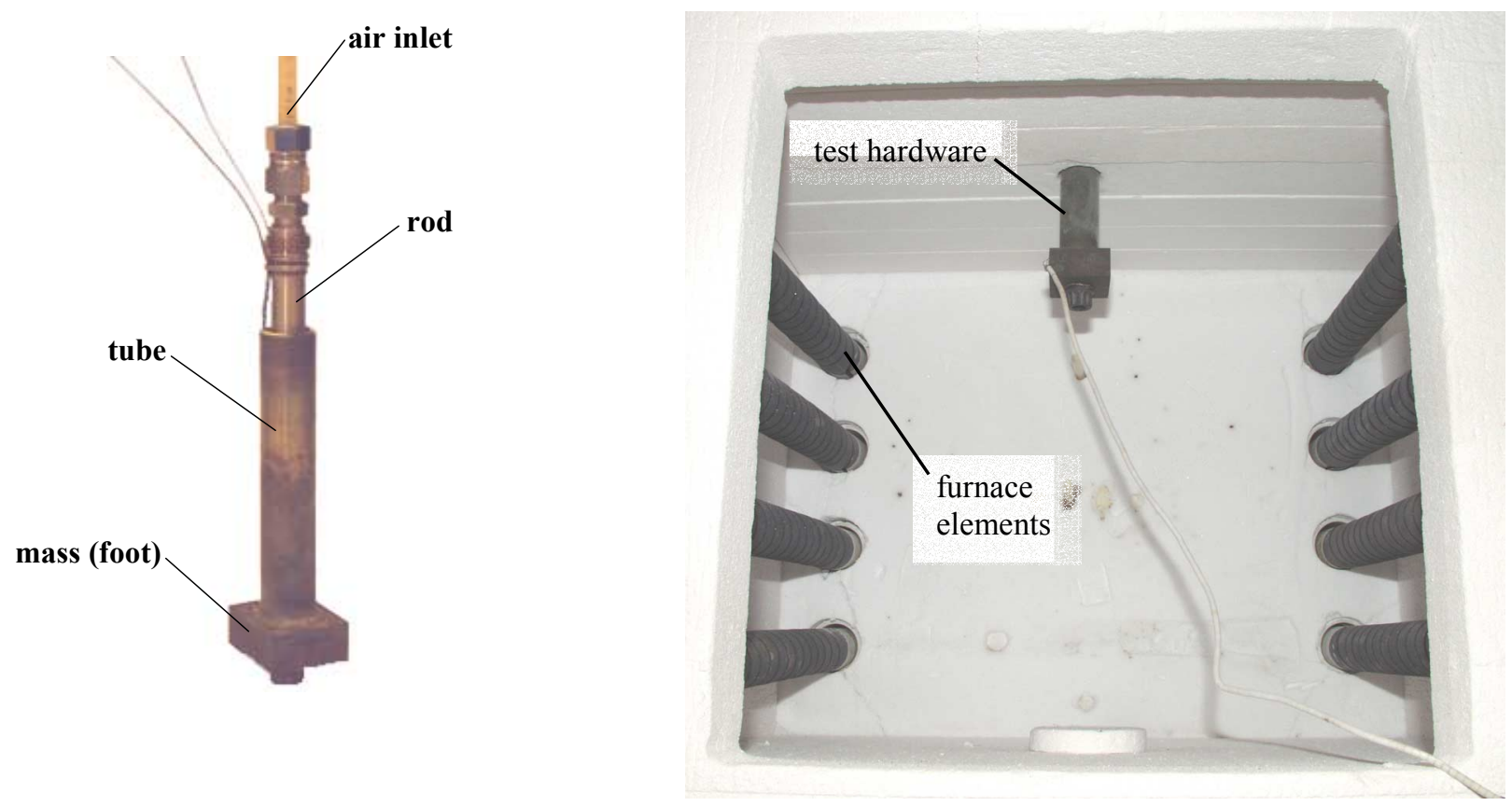

Figure 12: Cooled Rod Test Hardware and Furnace Assembly 


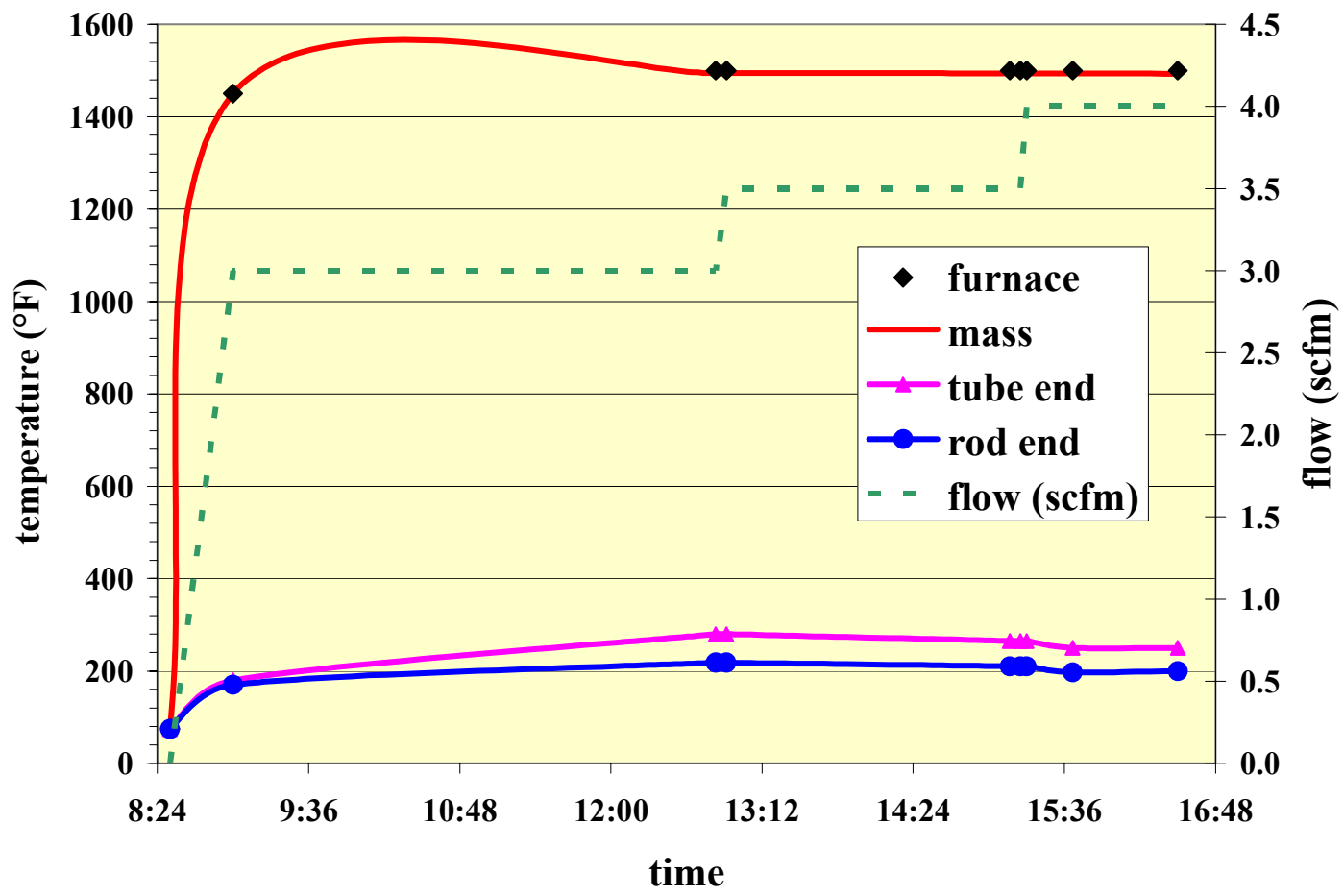

Figure 13: Cooled Rod Experimental Results

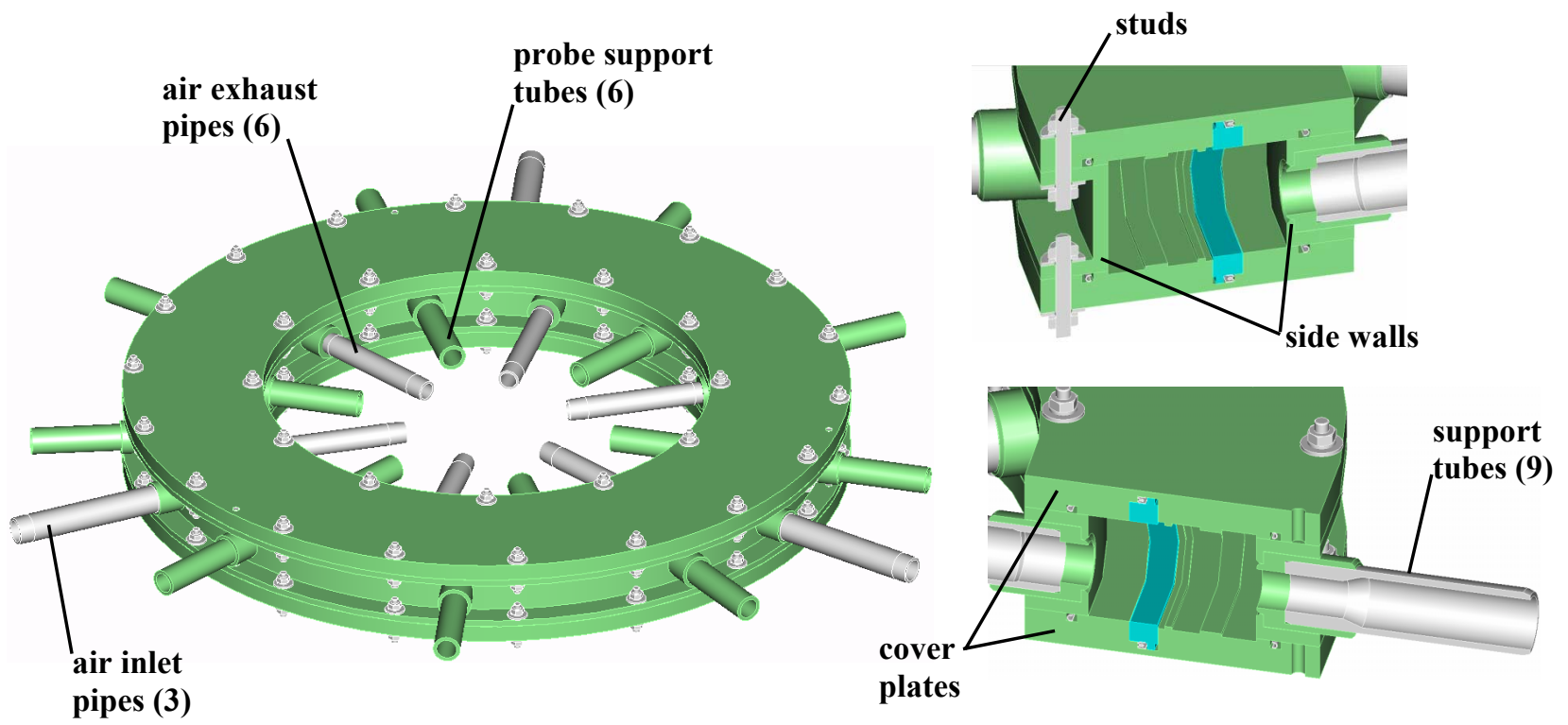

Figure 14: Chamber Assembly 


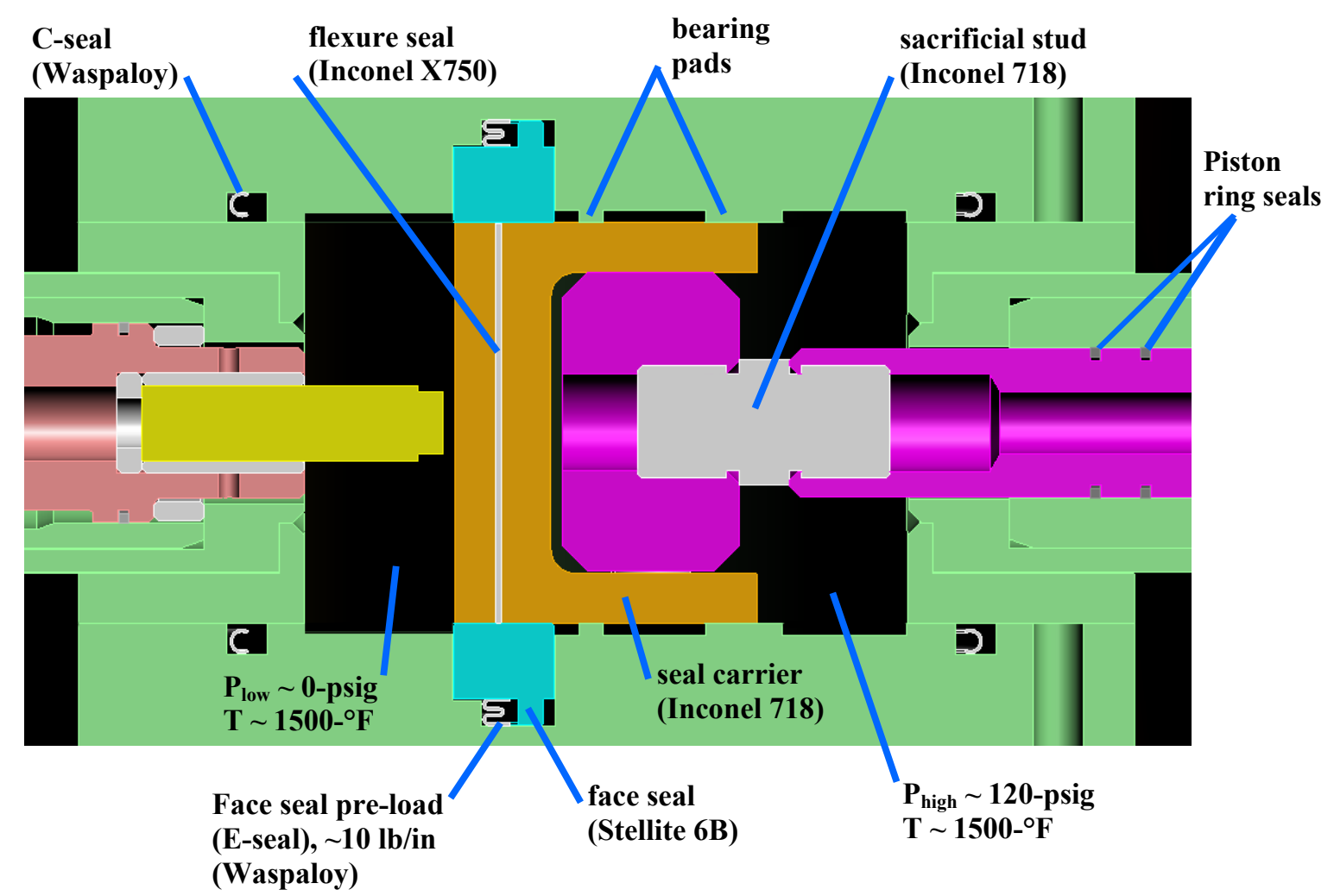

Figure 15: Chamber Detail and Seal Locations

be discussed in a later section, the figure shows that the upper and lower cover plates contain bearing pads to prevent the carrier segments from cocking as they are radially displaced. The carrier segments will operate between the cover plate bearing pads with a 0.006-in total clearance.

A series of tubes protrude from outer and inner sides of the chamber in the radial direction. Bosses that are welded to the sidewalls of the chamber support the tubes. The tubes are fixed to the bosses via press-fit or threaded arrangements, depending on their function. The tubes that are used for support, alignment, and air exhaust are press-fit into the bosses while the tubes that are used to supply/exhaust air to/from the chamber are threaded into the bosses. A standard boss design was used for ease of manufacturing.

\section{$\underline{\text { Support Tubes }}$}

Nine tubes that are equally spaced provide support and alignment for the entire chamber assembly. The support tubes are made of Inconel 718 and have outer and inner diameters of 1.25 -in and 1.0-in, respectively. The inner diameter necks down to 0.75 -in to provide alignment and support to the actuator rod ends as shown in Figure 11.

\section{Probe Support and Air Exhaust Tubes}

Twelve common tubes are assembled around the inner chamber wall. These tubes, also made of Inconel 718, provide support for the proximity probe fixtures as well as exhaust ports that allow the air that leaks past the carrier segments to be vented out of the rig. A common tube design was used to allow interchanging of exhaust ports and instrumentation depending on research needs, as well as for ease of manufacturing.

\section{Proximity Probe Fixture}

The proximity probes are held at a constant standoff to the chamber inner wall via a spring-loaded piston arrangement as shown in Figure 16. The sensor is held inside the end of a probe fixture tube via a split bushing and two set screws. The fixture tube houses a metal ring seal that blocks the air leaking past the carrier assembly from passing between the fixture tube and the probe support tube. A spring is engaged between the fixture tube end and a plug that is threaded into a boss that is clamped to the inner housing cylinder via a snap ring and washer arrangement. The spring forces the shoulder of the fixture tube against a spacer seated inside the boss. The spring-loaded mounting keeps the proximity sensor at a relatively constant position to the chamber inner sidewall during the initial heating of the 


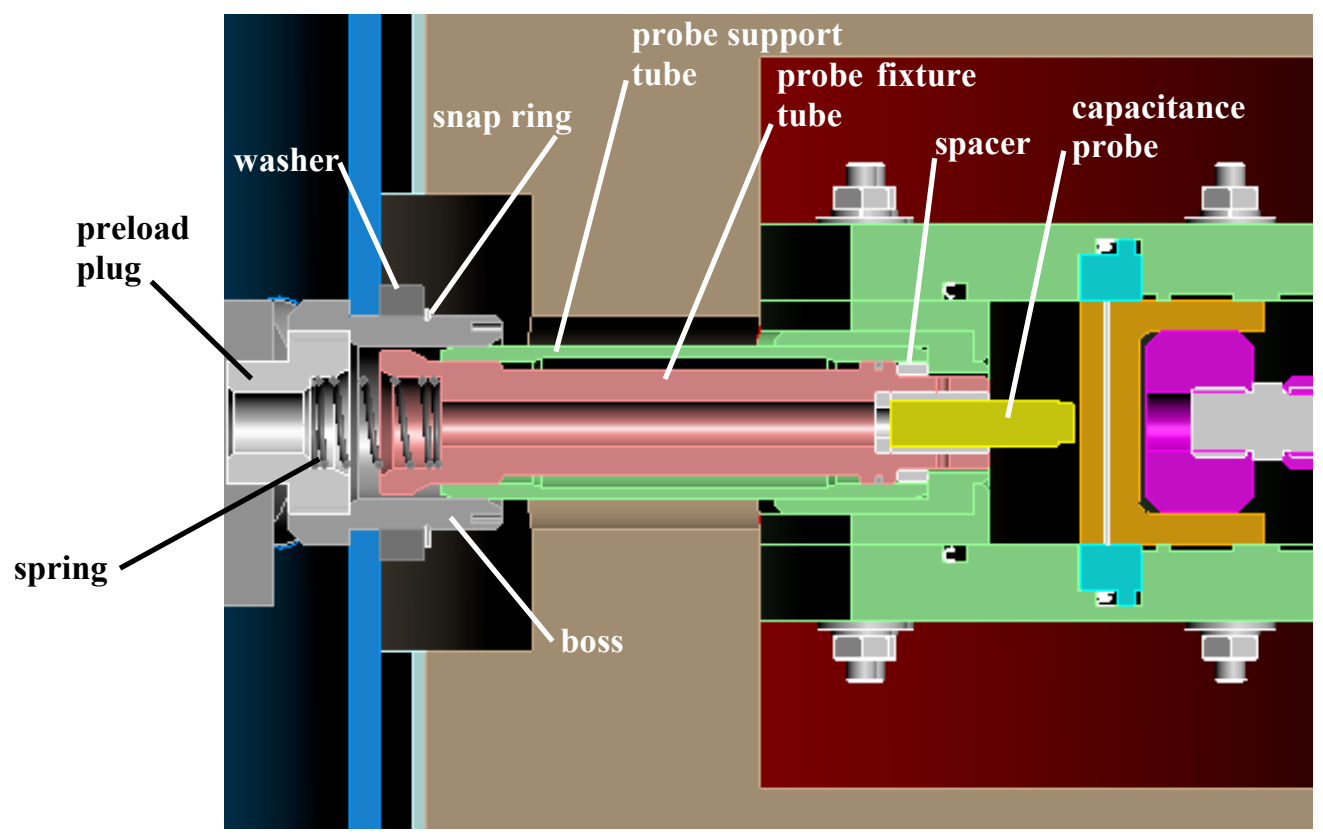

Figure 16: Proximity Probe Fixture Assembly

rig. This arrangement also allows for easy removal of the probes without dismantling the housing.

\section{Chamber Structural Analysis}

The chamber walls, cover plates, and supporting structures were designed to maintain their maximum stresses below 15-kpsi to ensure a minimum life of 300 hours under the maximum conditions of 120-psi and $1500{ }^{\circ} \mathrm{F}$. In particular, the cover plate was designed to minimize deflection, ensuring the assembly maintained adequate preload on the face seal. Figure 17 shows the stress and displacement results from a structural analysis of the cover plate. This conservative analysis included a 120-psi pressure load across the entire plate at $1500^{\circ} \mathrm{F}$, along with the C-seal and E-seal compression loads of $300-\mathrm{lbf} / \mathrm{in}$. and $10-\mathrm{lbf} / \mathrm{in}$., respectively. The figure shows that maximum deflection occurs at the E-seal groove, as would be expected due to the reduced thickness of the section. The maximum deflection ( $\sim 0.0043$-in.) is well below the E-seal compression of 0.015 -in. Maximum stresses are shown to be below the 15 -kpsi design limit except around the bolt-hole regions. The higher stresses along these regions are believed to be an artifact of the constraints applied to the bolt-holes and are believed not to be of concern.

\section{$\underline{\text { Seals }}$}

Although the shroud seals for the ACC system are not being utilized in the test rig, there are a number of secondary seals required due to the nature of the ACC system and rig designs.

\section{Flexure Seals}

Flexure seals, shown in Figures 8 and 9, are used to prevent the radial flow of pressurized air between the carrier segment joints. The 2.0 -in. wide by 0.9 -in. long flexures are made of 0.02-in. Inconel X750 sheet stock. This material was again chosen for its galling resistance to the carrier material. The carrier slits that contain the flexures are designed with a 0.01-in. clearance. The seals use the pressurized air to seat themselves, sealing on the lower slit surface of the carriers. The slit in one carrier segment is parallel to the slit of the adjoining of the carrier segment, making the flexure seal surface normal to the radial flow. The angles of the slits vary no more than $0.5^{\circ}$ over the 0.2 -in. stroke of the carrier segments. The bending stress in the flexures $(\sim 10-\mathrm{ksi})$ created by a 120-psig pressure load is well below the 15-kpsi limit.

\section{Flange Seals}

The chamber contains four "C-seals", two on the upper and lower outer diameter flanges and two on the upper and lower inner diameter flanges of the cover plates as shown in Figure 15. The seals are made of Waspalloy and have a cross sectional thickness of 0.02 -in. The seals were designed by Perkin-Elmer Fluid Sciences (Beltsville, MD) to seal against a 120 -psi pressure at $1500{ }^{\circ} \mathrm{F}$ and they require a 300-lbf/in. seating load per seal at assembly. Waspalloy has excellent high temperature strength and creep resistant properties as well as good wear resistance to nickel-based alloys. 

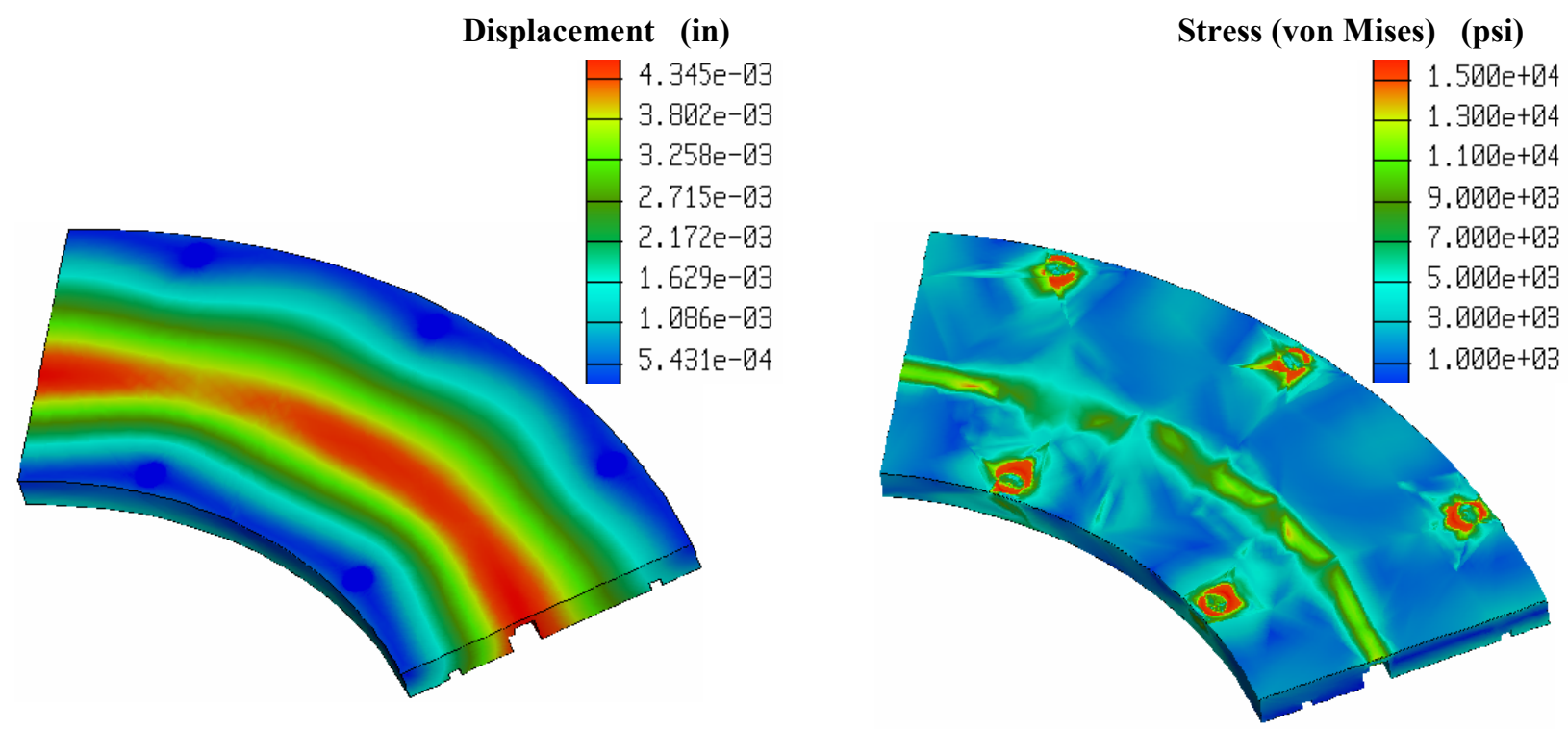

Figure 17: Chamber Cover Plate Structural Analysis Results

\section{Face Seals}

The upper and lower cover plates also house a metal face seal assembly, shown in Figure 15. These seals act to block the pressurized air from flowing between the cover plates and carrier segments. The face seal, made of Stellite $6 \mathrm{~B}$, is a pressure balanced design and utilizes an "E-seal" as a preload and secondary seal device. Stellite 6B was selected for the face seal material due to its high temperature properties and anti-galling performance against Inconel 718. The E-seals, also designed by Perkin-Elmer Fluid Sciences and made of Waspalloy, provide a closing force to the face seal on the carrier segments and prevent air from leaking between the face seal and cover plate. Each E-seal provides about $10-\mathrm{lbf} / \mathrm{in}$. preload to its corresponding face seal. The face seal was designed with a generous cross section, due to its large diameter, to provide stiffness for operation as well as manufacturing. Future studies will investigate alternate face seal designs based on the performance of the current design. The sealing surface of the face seals is to be manufactured with an 8-RMS finish and a flatness of 0.0003-in. The carrier segments are to be finish ground as an assembly with the flexure seals in place. The outer sides of the carrier assembly are to be held to an 8-RMS finish, a flatness of 0.0003 -in. and parallel to 0.0005 -in.

\section{$\underline{\text { Ring Seals }}$}

The actuator rod contains two pairs of expanding concentric ring seal sets on its bearing surface as shown in Figure 11. Each pair is made of an outer Stellite 25 ring and an inner Inconel 625 ring. The outer ring has a rectangular cross section (approximately 0.022-in. high by 0.05 -in. wide) with a step cut gap configuration (lap joint) and a gage gap of approximately 0.025 -in. The inner ring has a rectangular cross section (approximately 0.02 -in. high by 0.05 -in. wide) with a square cut gap configuration (butt joint) and a gage gap of approximately 0.045 -in. The seals were designed by Precision Rings, Inc. (Indianapolis, IN) for a 120-psi at $1500{ }^{\circ} \mathrm{F}$.

\section{Seal Leakage}

Figure 15 shows the main seal locations, and hence leakage paths, of the chamber and carrier assemblies. The main locations of concern are between the sides of the carriers and the chamber cover plates, the chamber outer flange, between the joints of the carriers, and along the actuator rods. As previously discussed, most of the seals were of a standard design (metal ring seals, "C-seals", "E-seals). The leakages of these seals were provided by the corresponding manufacturer, based on the conditions specified. The face and flexure seals, however, were designed by the authors and their leakages had to be calculated. The details of the steps taken and equations used for those procedures are provided for the reader in the Appendix of this work. The approaches are summarized below. The leakage results, either provided by the seal manufacturer or estimated by the authors, are given in Table 1 .

\section{$\underline{\text { Face Seal }}$}

Because of the moderate pressure drop across the face, calculating the leakage between the face seal and carrier surfaces required the authors to determine whether the flow was choked or not. The procedure involved an 


\begin{tabular}{|c|c|c|c|}
\hline location & $\begin{array}{c}\text { pressure } \\
\text { drop (psi) }\end{array}$ & $\begin{array}{c}\text { temperature } \\
\left({ }^{\mathbf{}} \mathbf{F}\right)\end{array}$ & $\begin{array}{c}\text { flow } \\
\text { (scfm) }\end{array}$ \\
\hline $\begin{array}{c}\text { C-seal } \\
\text { (outer) }\end{array}$ & 120 & 1500 & 1.6 \\
\hline ring seals & 120 & 1500 & 0.6 \\
\hline $\begin{array}{c}\text { flexure } \\
\text { seals }\end{array}$ & 120 & 1500 & 23.3 \\
\hline face seals & 120 & 1500 & 2.1 \\
\hline E-seals & 120 & 1500 & 5.4 \\
\hline total & & & $\mathbf{3 3 . 1}$ \\
\hline
\end{tabular}

Table 1: Seal Leakage

iterative process using the equations of onedimensional, radial, adiabatic flow between two parallel surfaces. ${ }^{12}$ An inlet Mach number was iterated for such that choked conditions were achieved at the outlet. The outlet pressure was then compared to ambient to verify if choking actually occurred. Using this procedure, the authors found that the flow was not choked anywhere along the flow path and that the leakage across the face was approximately 1.0 -scfm (per seal).

\section{Flexure Seals}

The authors estimated a worst-case scenario for the flexure seal leakage and assumed choked flow through the clearance area between the carrier slots and the flexures. Calculating the flow in this manner provided an upper bound on the leakage through the carrier segment joints. The authors assumed a seated clearance between the carrier slots and the flexures of 0.0005 -in. This clearance gives an area of $0.001-$ in. $^{2}$, with the carrier width at 2.0-in., per flexure seal. Equation 4 gives a relation for the maximum mass flow of air through an area under choked conditions. ${ }^{13}$

$$
\dot{\mathrm{m}}_{\max }=0.6847 \frac{\mathrm{p}_{\mathrm{o}} \mathrm{A}^{*}}{\sqrt{\mathrm{RT}_{\mathrm{o}}}}
$$

The choked flow assumption produced a total flow of 23.3-scfm as shown in Table 1.

\section{Heating Systems}

The test rig utilizes two heating systems to simulate the thermal environment of the shroud seal backsides that are cooled at 1200 to $1300^{\circ} \mathrm{F}$ in an actual turbine engine.

\section{$\underline{\text { Radiant Heater Design }}$}

The radiant heater is formed from two halves ("U" shaped in cross section) that enclose the chamber in a rectangular annulus as shown in Figure 7. The body of the heater is made of a lightweight alumina-silica fiber composition. The heating elements, made of an ironchrome-aluminum composition, are embedded under the annular surface in a flat sinuated pattern. The ceramic fiber body has a density and thermal conductivity of approximately $0.15 \mathrm{lbm} / \mathrm{ft}^{3}$ and

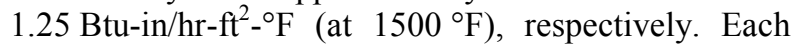
radiant heater will be contained in a housing, made of 0.062 -in. thick stainless steel sheet. The housings will provide molds for the ceramic fiber bodies during manufacturing and a protective shell for assembly into and out of the rig. Porcelain bushings isolate the heating element power leads from the heater and main housings.

\section{Element Zones}

The heating elements for both the upper and lower halves of the heater are to be wired in six separate circumferential zones. Each zone from the lower half will be wired in parallel to its corresponding zone in the upper half such that each circumferential zone (upper and lower) will be powered through one controller. This will give researchers the ability to heat the chamber in a non-uniform fashion, simulating the phenomenon that can occur in an actual engine, where shroud seal backside temperatures can vary by $150^{\circ} \mathrm{F}$ from the twelve to six o-clock positions.

\section{Control System}

Figure 18 shows the basic control logic used for the radiant heater system. Power is brought to the heating elements through a fused disconnect. Each of the twelve circumferential zones (upper and lower) will have thermocouples to measure both element and air temperatures. Cascade control will be used such that the desired zone air temperature can be reached and maintained while preventing element burnout. Air and element temperatures are fed into a process controller and a high limit controller, respectively. The process controller sets and maintains the process air temperature. The high limit controller automatically cuts power to all of the heating elements if any element reaches the high temperature limit setting to prevent element burnout.

\section{Air Heater system}

The purpose of the air heater is to allow pressurization of the chamber, and hence pressure loading of the 


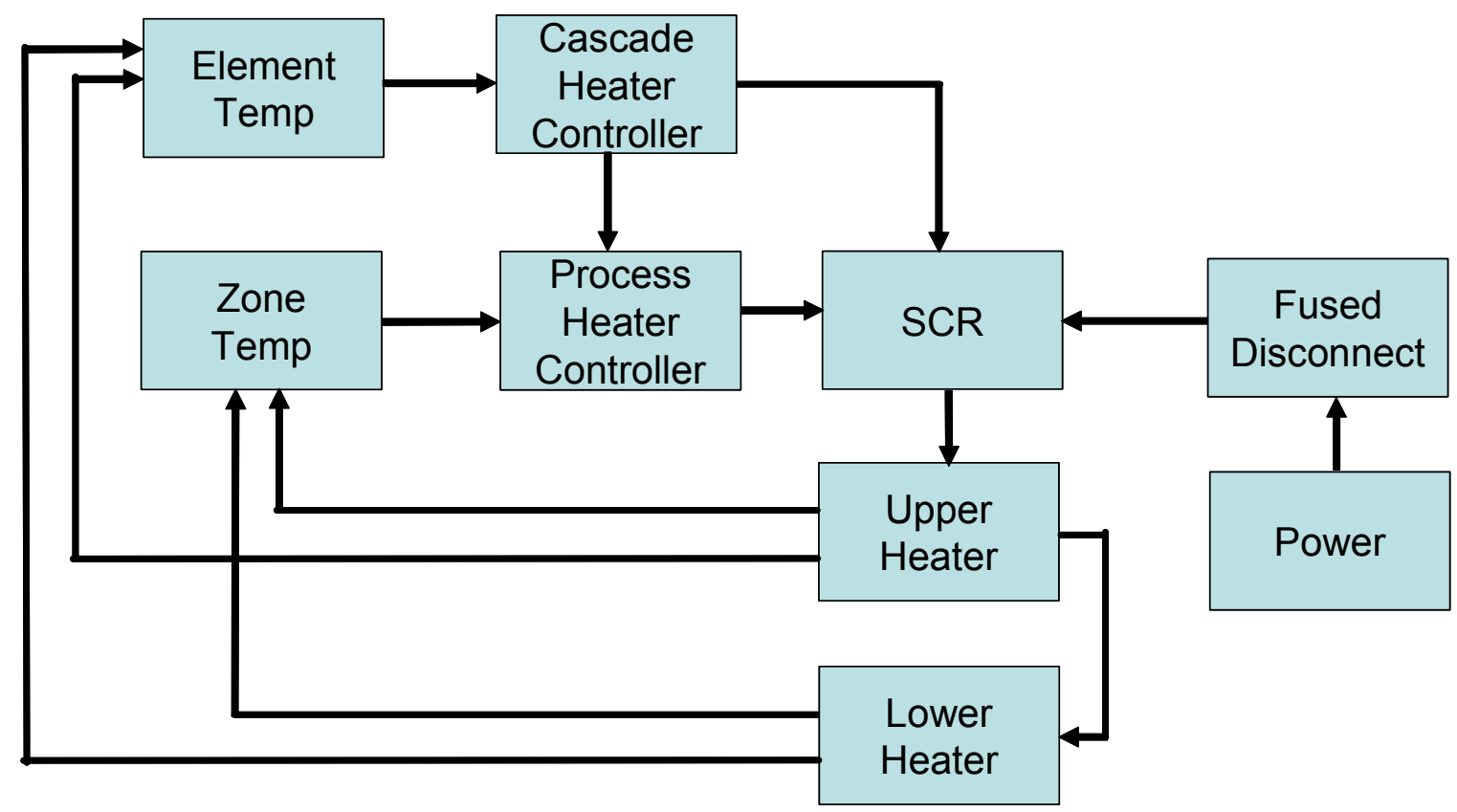

Figure 18: Radiant Heater Control Diagram

carrier assembly, in a relatively isothermal environment. Because the seals described in previous sections are not "air-tight", leakage past the carrier assembly and actuators rods will occur. While the leakage was calculated to be relatively small $(\sim 30$-scfm), large temperature variations between hot section components and the pressurized air can cause thermal distortions of the components at the leakage locations. To mitigate non-uniform thermal distortion of components, the authors sized an air heating system to minimize the temperature difference between the pressurized air and the radiant heater as well as utilizing a baffle to deflect the air flow in a uniform fashion around the chamber annulus. While the authors did not expect to have to supply a large amount of flow to the rig, providing even low flow rates (below 100-scfm) of heated air at $1500^{\circ} \mathrm{F}$ and 120 -psi can be challenging.

\section{Heater Design}

The heater was designed to supply up to 80 -scfm of air at 120 -psi and $1500^{\circ} \mathrm{F}$. The heater is made of two 36-kW, inline, flanged heaters, manufactured by Osram Sylvania (Danvers, MA) that are used in series to achieve the $1500^{\circ} \mathrm{F}$ temperature specification. Each heater is composed of six heating elements housed in a 304 stainless steel schedule 80 pipe that has $300-1 b f$ welded flanges on either end. The elements are wired such that each pair is on one phase of the three-phase power supply. Air, supplied to the housing, flows through cylinders that enclose the individual heating elements that line the inner diameter of the housing. The heaters are supplied with thermocouples to measure element temperature and the process air temperature at the exit of the housing to prevent element burnout.

\section{Control System}

Figure 19 shows the basic control logic used for the air heater system. Power is brought to the heating elements through a fused disconnect. Process air and element temperatures are fed into a process controller and a high limit controller, respectively. The process controller sets and maintains the process air temperature. The high limit controller automatically cuts power to all of the heating elements if any element pair reaches the high temperature limit setting to prevent element burnout.

\section{Housing}

The housing shown in Figure 5 is made of 304 stainless steel. The housing is made of two concentric cylinders that make up the annular walls, a base plate and lid. The annular cross section dimensions of the enclosed housing are 13.5 -in. wide by 12 -in. high. Each cylinder is made of 0.25 -in. plate that is rolled and welded together. The inner cylinder has an inside diameter of 9.0-in., while the outer cylinder has an outer diameter of 37 -in. The cylinders are welded to the base plate that forms the main housing.

Stainless steel bosses, 7.5-in. in diameter, are welded to the outer annular wall of the housing to support the actuator mounts. The bosses provide adequate depth of 


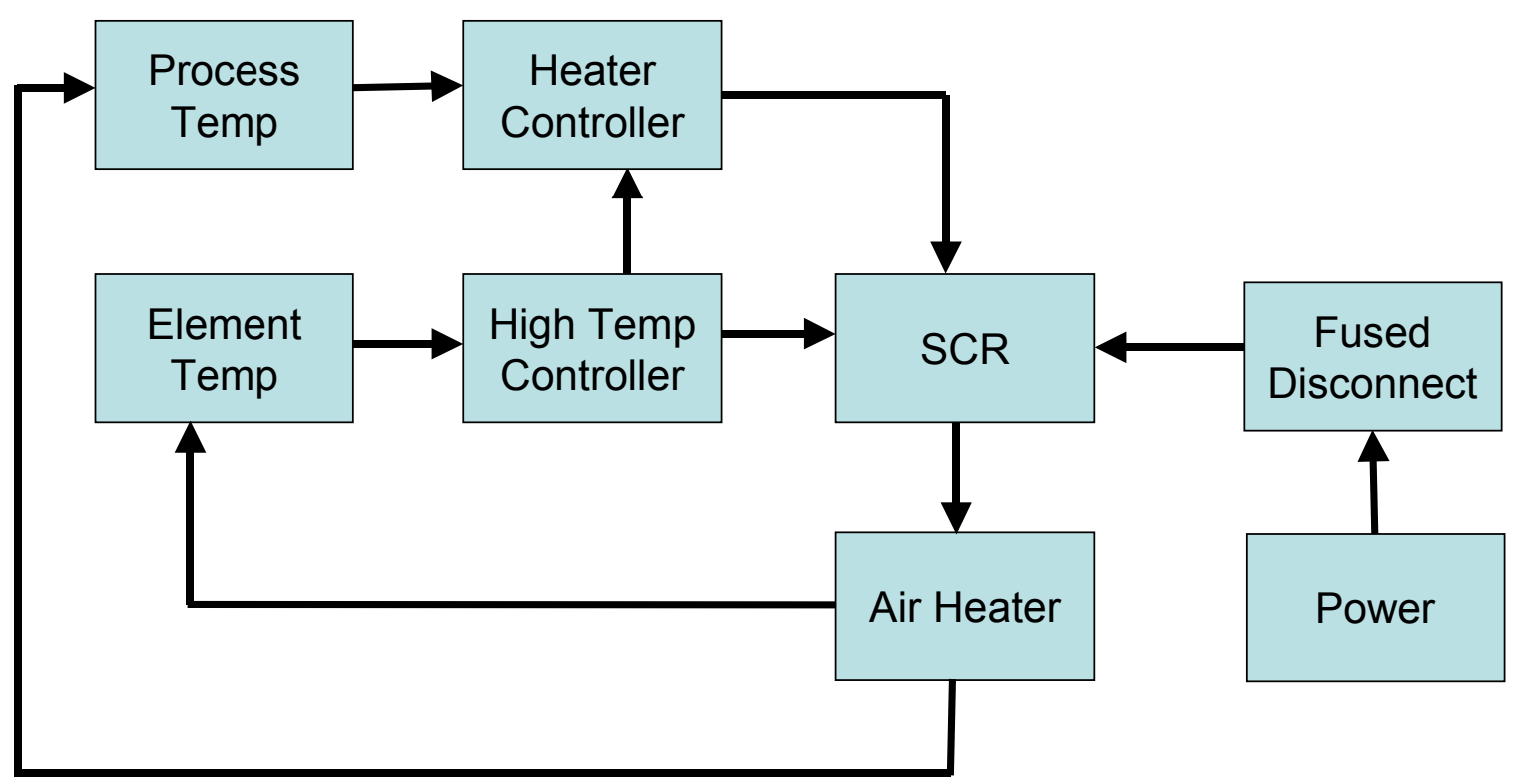

Figure 19: Air Heater Control Diagram

section through which the actuator mounts are bolted. The bosses also serve to make the rig design modular, in that different actuator mounts and actuators can be "plugged" into the rig and tested.

The base plate contains pressure vent ports in case the chamber should leak, such that the housing will never become a pressure vessel. The main housing outer wall and lid contain lifting eyes for transporting the entire assembly

\section{Actuator Mounts}

The actuator mounts provide supporting and aligning structures for the actuators and the actuator rods, as well as inlet and exhaust ports for the actuator rod cooling air (Figure 11). The actuator mount's inner diameter provides an aligning and bearing surface for the actuator rod end. Each mount contains a metal ring seal to prevent exhaust cooling air from flowing into the radiant heater and two high temperature elastomeric o-rings that prevent the inlet cooling air from flowing along the outer surface of the actuator rod.

\section{Housing Pedestal}

The entire assembly is supported off the inner housing wall and base plate via an annular pedestal (see Figure 7). The pedestal flange is bolted to the test stand table and housing base plate. The flange holes for the housing bolts are oversized to prevent rotation of the assembly while allowing for thermal expansion of the inner cylinder wall. The bottom of the outer housing wall is notched out to provide support skids for the housing while allowing for thermal expansion of the outer cylinder wall (see Figures 5 and 6).

\section{Customized Hydraulic Actuator}

The authors are currently designing a low profile, servo-controlled, hydraulic actuator. Industrial hydraulic actuators, which met the specified the load, stroke, response, and accuracy requirements, were found to occupy too much space for flight hardware. The authors decided to design a custom actuator using standard components of current, high accuracy, and robust hydraulic actuator systems.

\section{Actuator Design}

The present hydraulic actuator design is shown in Figure 20. The actuator is comprised of a cylinder section, servo valve and position sensor. The cylinder is constructed with low friction and high temperature seals for minimal hysteresis. The actuator cylinder works against a mechanical spring load so that the ACC system would fail open in the event of hydraulic pressure loss. Mechanical stops are included to prevent over-travel of the carrier segments. The servo valve is a digital control with internal feedback for positional accuracy.

The system is designed for a 0.20 -in. stroke with a cycle rate of 25 seconds per inch and a 3 -in. bore piston. The actuator occupies a length of about 6.5 -in. Half of the length comes from a commercially available displacement transducer that runs inline with the cylinder centerline. This length could be further reduced using a custom designed transducer. 


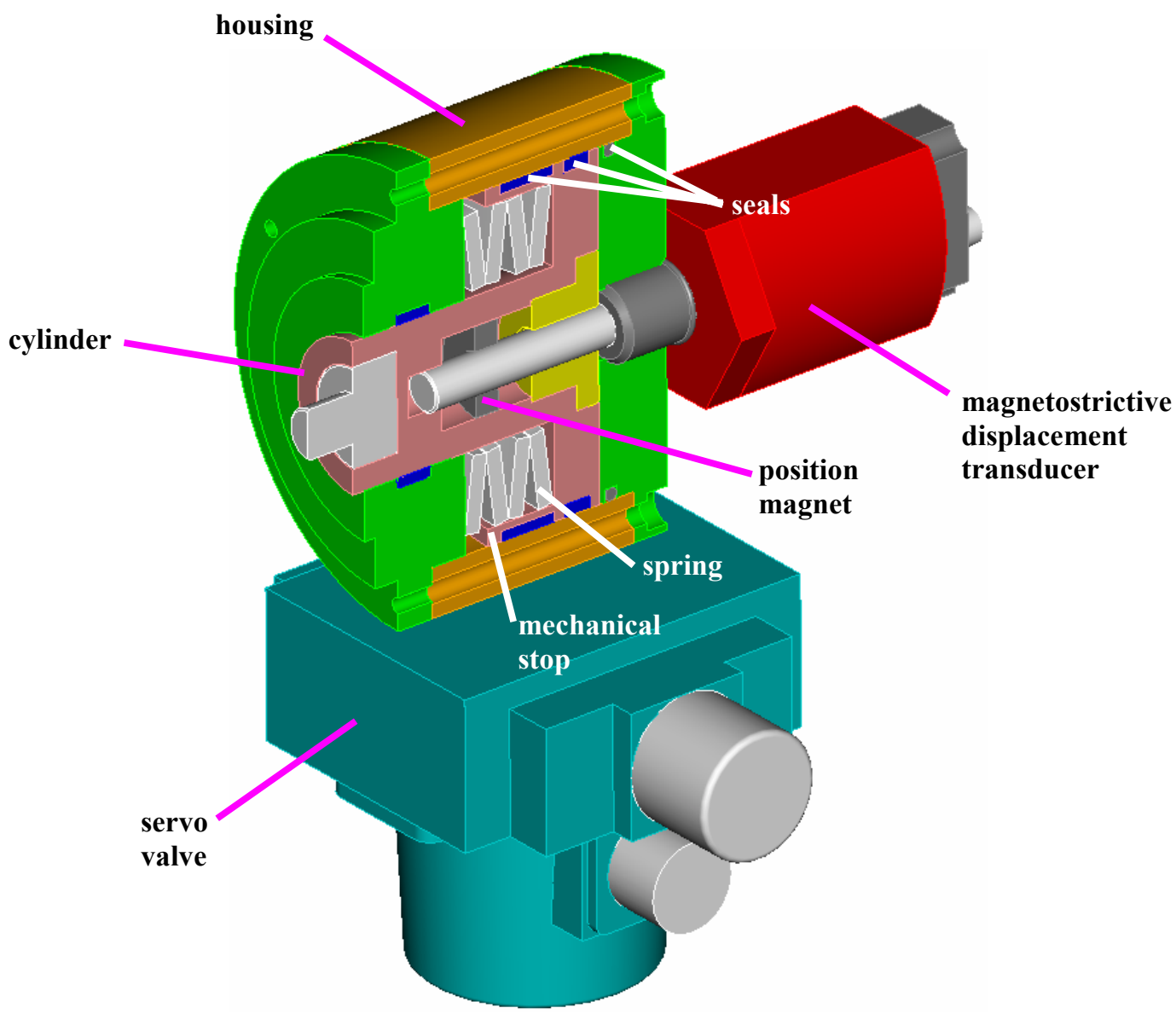

Figure 20: Custom Actuator Design

\section{Control System}

Figure 21 shows the basic control logic to be used for the independently controlled hydraulic actuators. A feedback control system utilizes displacement measurement of both the cylinder and carrier segments. The set point (or clearance) is input to the controller which then activates the servo valve. The cylinder is accurately displaced as its position is fed back to the servo. The carrier displacement is then checked against the initial set point by the controller.

\section{Accuracy}

The servo system has a 0.0003 -in. positional accuracy with full velocity and acceleration profile capabilities. The displacement transducer employs magnetostrictive technology with digital output and is capable of a 0.00008 -in. resolution. Coupled with the capacitancebased probes and the hardware tolerance specifications, the actuator will have positioning capabilities of 0.001 -in. under full load.

\section{Instrumentation}

The test rig is equipped with a great deal of instrumentation. Measurements of displacement, temperature, pressure, and flow rate will provide researchers necessary data for evaluation of actuator concepts, monitoring environmental conditions of the rig, feedback control for rig operation, and health monitoring of the rig and support systems.

\section{Capacitance Sensors}

High-temperature capacitance-based proximity probes (manufactured by Capacitec of Ayer, Massachusetts) will be utilized to measure the displacement rate and position of the carrier segments, as shown in Figures 7 and 16. Four probes will be positioned such that three are equally spaced at $120^{\circ}$, while two probes are positioned $180^{\circ}$ apart. The probe positioning will allow the measurement of an effective and true shroud diameter. The probes will target the ends and midpoints of various carrier segments to evaluate the 


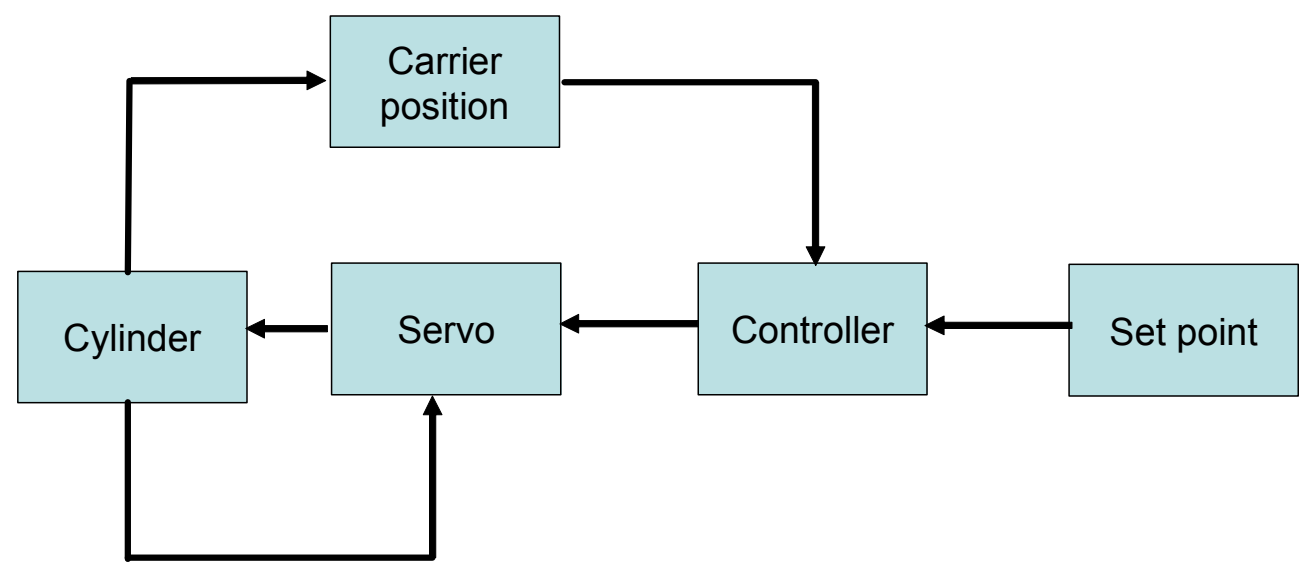

Figure 21: Actuator Control Logic

positioning accuracy and repeatability of the independent actuators. The probes chosen for this work have a body diameter of 0.375 -in. and length of 1.5 -in. The probes have a linear range of 0.100 -in., an accuracy of 1.0E-5-in., a resolution of 1.0E-7-in., and can function in environments up to $1832^{\circ} \mathrm{F}$. The signal amplifiers have a frequency response of $15-\mathrm{kHz}$. The probes were calibrated by the manufacturer at various temperatures ranging from 300 to $1500^{\circ} \mathrm{F}$. The test rig is designed to permit the evaluation of other displacement probes currently under development.

\section{Temperature}

Temperature measurements will be utilized in quantifying the thermal environment in which components will be evaluated, controlling the air and radiant heater systems, and health monitoring of various components. A standard thermocouple design of a type-K, grounded bead with a 0.063 -in. diameter, 12 -in. long sheath (Inconel 600) will be utilized throughout the rig. All thermocouples that protrude the main housing will be fixed to the housing base or lid via compression fittings. The chamber air temperatures will be measured at three circumferential locations on the high-pressure side of the carriers. Two thermocouples will be positioned near two of three chamber air inlets and one will be positioned between two air inlets. These thermocouples will show how well the pressurized air is mixed by the chamber baffle.

The chamber flange metal temperatures will be measured via two surface thermocouples attached to the inner and outer flange on the lower cover plate. These thermocouples will straddle one of the air thermocouples as shown in Figure 7. One of the nine actuator rod ends will have a thermocouple to monitor the rod cooling system and will determine how much pressure should be used for the cooling air supply.

\section{Pressure}

Pressure of the inlet air to the chamber will be measured via pressure transducers off the air inlet pipes before entering the rig with static pressure taps. This will provide the high-side chamber pressure. Pressure will also be measured off of the exhaust pipes to ensure no backpressure exists in the chamber vent.

\section{Flow}

The inlet air mass flow will be measured with a flow meter prior to entering the air heater. This flow will indicate the chamber air leakage and hence health of the secondary seals. This measurement will be particularly important for the life of the face and flexure seals, in that they are in the most challenging environments with temperature, pressure, and displacement.

\section{CONCLUSIONS}

The design of a first generation, hydraulically powered mechanical system to provide active clearance control for turbine blade tip shroud seals along with a test rig to evaluate its response and positioning accuracy has been presented. The system employs a segmented seal carrier structure, independent hydraulic actuators, high temperature proximity probes, and feedback control. The ACC system has been designed to accurately position the carrier segments, and hence clearance of the shroud seal, to within 0.004-in. or less. The ACC system and test rig have been designed to function at pressures up to 120-psi and temperatures up to $1500^{\circ} \mathrm{F}$ with a minimum cycle life of 300 hours at these maximum conditions.

The ACC system developed in this work will be evaluated in the previously described test rig under a series of temperature and pressure conditions to evaluate its performance in a simulated turbine environment. The results of this testing will be used to 
further develop the current actuator design as well as other actuator concepts. ACC system components will be optimized to increase cycle life while reducing weight for future flight hardware development.

\section{NOMENCLATURE}

A cross sectional area of rod, in. ${ }^{2}$

ACC Active clearance control

Btu British thermal unit

C Larson-Miller constant, 20

CDP Compressor discharge pressure

$\mathrm{C}_{\mathrm{p}} \quad$ specific heat of air, Btu $/ \mathrm{lbm}-{ }^{\circ} \mathrm{F}$

$\mathrm{C}_{\mathrm{L}} \quad$ Flow loss coefficient

EGT Exhaust gas temperature

$\mathrm{f}^{\text {' }} \quad$ friction factor

FAA Federal Aviation Administration

$\mathrm{ft} / \mathrm{s} \quad$ Feet per second

$\mathrm{h} \quad$ Clearance, in.

HPC High pressure compressor

HPT High pressure turbine

hr Hours

in. Inches

k Thermal conductivity, Btu-in $/ \mathrm{ft}^{2}-\mathrm{hr}-{ }^{\circ} \mathrm{F}$

$\mathrm{krpm} \quad$ (Revolution per minute) $\times 1000$

lbf Pound force

$\mathrm{lbf} /$ in. Pound force per inch

lbf Pound mass

$\mathrm{L}$ length of rod, in.

LCC Life cycle cost

LPT Low pressure turbine

M Mach number

$\mathrm{M}_{1} \quad$ inlet Mach number

$\mathrm{M}_{2} \quad$ outlet Mach number m Mass flow of air, $\mathrm{lbm} / \mathrm{hr}$

P Larson-Miller Parameter

$\mathrm{p}_{1} \quad$ Inlet pressure, $\mathrm{psi}$

$\mathrm{p}_{2} \quad$ Outlet pressure, $\mathrm{psi}$

$\mathrm{P}_{3} \quad$ Air pressure exiting high pressure compressor

PCC Passive clearance control

psi Pound-force per square inch

$\mathrm{q}_{\text {cond }} \quad$ Heat conducted through rod, Btu/hr

$\mathrm{q}_{\text {conv }} \quad$ Heat convected by mass flow, Btu/hr

$\mathrm{R} \quad$ Gas constant

Re Reynolds number

RMS Root mean square

rpm Revolution per minute

s Seconds

SFC Specific fuel consumption

$\mathrm{T}$ Temperature, Rankin

$\mathrm{t}$ Time to produce creep condition of interest (e.g. $0.5 \%$ creep strain), hours

$\mathrm{T}_{3} \quad$ Air temperature exiting high-pressure compressor

$\mathrm{T}_{\mathrm{c}} \quad$ Temperature of rod (cool end), ${ }^{\circ} \mathrm{F}$

$\mathrm{T}_{\mathrm{i}} \quad$ Temperature of air in, ${ }^{\circ} \mathrm{F}$

$\mathrm{T}_{\mathrm{h}} \quad$ Temperature of rod (hot end), ${ }^{\circ} \mathrm{F}$

$\mathrm{T}_{\mathrm{o}} \quad$ Temperature of air out, ${ }^{\circ} \mathrm{F}$

TOW Time-on-wing

$\mathrm{u} \quad$ Air velocity, $\mathrm{ft} / \mathrm{s}$

$\gamma \quad$ Specific heat ratio

$\lambda \quad$ Pressure ratio

$\mu \quad$ Dynamic viscosity, $\mathrm{lbm} / \mathrm{ft}-\mathrm{s}$

$\rho \quad$ Density, $\mathrm{lbm} / \mathrm{ft}^{3}$

$\circ \quad$ Angular Degrees

${ }^{\circ} \mathrm{C} \quad$ Degrees Celsius

${ }^{\circ} \mathrm{F} \quad$ Degrees Fahrenheit 



\section{$\underline{\text { APPENDIX }}$}

Face Seal Leakage Analysis

An entrance Mach number $\left(\mathrm{M}_{1}\right)$ was assumed, from which the inlet temperature, flow velocity, Reynolds number and friction factor are calculated using equations 5 to 8 , respectively.

$$
\begin{gathered}
\mathrm{T}_{1}=\frac{\mathrm{T}_{\mathrm{i}}}{1+\frac{(\gamma-1) \mathrm{M}_{1}^{2}}{2 \mathrm{C}_{\mathrm{L}}^{2}}} \\
\mathrm{M}=\frac{\mathrm{u}}{\sqrt{\lambda \mathrm{RT}}} \\
\operatorname{Re}=\frac{2 \rho \mathrm{h}}{\mu} \\
\mathrm{f}^{\prime}=\frac{\mathrm{k}}{\operatorname{Re}^{\mathrm{n}}}
\end{gathered}
$$

where for laminar flow $(\operatorname{Re}<2300), \mathrm{k}=24, \mathrm{n}=1$

and for turbulent flow $(\operatorname{Re}>3000), k=0.79, n=0.25$

The inlet pressure, $p_{1}$ is found from equation 9 based on a loss coefficient $\mathrm{C}_{\mathrm{L}} \cdot{ }^{14}$

The outlet Mach number, $\mathrm{M}_{2}$ is found via integration of equation 10 , which, with the assumption of a constant gap, gives the relation shown by equation 11 .

$$
\mathrm{p}_{1}=\frac{\mathrm{p}_{\mathrm{i}}}{\left[1+\frac{(\gamma-1) \mathrm{M}_{1}^{2}}{2 \mathrm{C}_{\mathrm{L}}^{2}}\right]^{\frac{\gamma}{\gamma-1}}}
$$

where $\mathrm{C}_{\mathrm{L}}=0.6$

$$
\begin{array}{r}
\frac{\mathrm{dM}^{2}}{\mathrm{dr}}=\left(\mathrm{f}^{\prime} \mathrm{M}^{2} \gamma-\frac{\mathrm{dh}}{\mathrm{dr}}\right) \frac{2 \mathrm{M}^{2}\left(1+\frac{\gamma-1}{2} \mathrm{M}^{2}\right)}{\mathrm{h}\left(1-\mathrm{M}^{2}\right)} \\
-\frac{1}{\gamma} \frac{1-\mathrm{M}^{2}}{\mathrm{M}^{2}}-\left.\frac{\gamma+1}{2 \gamma} \ln \left[\frac{\frac{1}{2}(\gamma+1) \mathrm{M}^{2}}{1+\frac{1}{2}(\gamma-1) \mathrm{M}^{2}}\right]\right|_{\mathrm{M}_{1}} ^{\mathrm{M}_{2}}=\frac{2 \Delta \mathrm{rf}^{\prime}}{\mathrm{h}}
\end{array}
$$

This process is repeated until an inlet Mach number is found such that a choked condition exists at the outlet $\left(\mathrm{M}_{2}=1.0\right)$.

The outlet pressure $p_{2}$ is then checked against the ambient pressure $p_{o}$ to determine if the flow is truly choked. This is the case if $p_{2}>p_{0}$. If $p_{2}<p_{o}$, then the flow is subcritical and $M_{1}$ must be found such that $p_{2}=$ $\mathrm{p}_{\mathrm{o}}$. The outlet pressure is calculated using:

$$
\mathrm{p}_{2}=\mathrm{p}_{1} \frac{\mathrm{M}_{1}}{\mathrm{M}_{2}}\left[\frac{1+\frac{\gamma-1}{2} \mathrm{M}_{1}^{2}}{1+\frac{\gamma-1}{2} \mathrm{M}_{2}^{2}}\right]^{\frac{1}{2}}
$$





\section{REFERENCES}

${ }^{1}$ Halila, E.E., Lenahan, D.T., Thomas, T.T., "Energy Efficient Engine, High Pressure Turbine Test Hardware Detailed Design Report," NASA CR-167955, 1982.

${ }^{2}$ Lattime, S.B., Steinetz, B.M., "Turbine Engine Clearance Control Systems: Current Practices and Future Directions," NASA/TM-2002-211794, 2002.

${ }^{3}$ Wiseman, M.W., Guo, T. "An Investigation of Life Extending Control Techniques for Gas Turbine Engines," Proceedings of the American Control Conference, Arlington, VA, June 25-27, 2001.

${ }^{4}$ Rocky Mountain Institute (RMI), "Climate, Air Travel Emissions," 2002.

${ }^{5}$ European Regions Airline Association (ERA), "ERA Fast Facts," September 2001.

${ }^{6}$ Olsson, W.J., Martin, R.L., "B747/JT9D Flight Loads and Their Effect on Engine Running Clearances and Performance Deterioration; Nacelle Aerodynamic and Inertial Loads (NAIL)/JT9D Jet Engine Diagnostics Programs," NASA CR-165573, 1982.

${ }^{7}$ Martin, R.L., "Nacelle Aerodynamic and Inertial Loads (NAIL) Project, Test Report," NASA CR-165760, 1981.

${ }^{8}$ Electronic Code of Federal Regulations, Title 14, Aeronautics and Space, Chapter I, Federal Aviation Administration, Department of Transportation, Part 33, Airworthiness Standards: Aircraft Engines, 33.73 Power or Thrust Response, Amdt. 33-1, 36 FR 5493, Mar. 24, 1971.

${ }^{9}$ Juvinall, R.C., "Engineering Considerations of Stress, Strain and Strength," Creep and Creep Rupture, 1st ed., McGraw-Hill, New York, 1967, pp. 416-417.

${ }^{10}$ Laskowski, J.A., Dellacorte, C., "Friction and Wear Characteristics of Candidate Foil Bearing Materials from $25^{\circ} \mathrm{C}$ to $800{ }^{\circ} \mathrm{C}$," Proceedings of the Society of Tribologists and Lubrication Engineers 51st Annual Meeting, Cincinnati, OH, 1996.

${ }^{11}$ Incropera, F.P., Dewitt, D.P, "Introduction to Heat Transfer," Physical Origins and Rate Equations, 1st ed., John Wiley \& Sons, New York, 1985, pp. 5-8.

${ }^{12}$ LeBeck, A.O., "Principles and Design of Mechanical Face Seals," Seal Interface Tribological Modeling, 1st ed., John Wiley \& Sons, New York, 1991, pp. 133-138.

${ }^{13}$ White, F.M. "Fluid Mechanics," Isentropic Flow with Area Changes, 1st ed., McGraw-Hill Book Company, New York, 1979, pp. 529-530.

${ }^{14}$ Zuk, J., "Analytical Study of Pressure Balancing in Gas Film Seals," ASLE Transactions, vol. 17, 1974, pp. 97-104. 
Public reporting burden for this collection of information is estimated to average 1 hour per response, including the time for reviewing instructions, searching existing data sources, gathering and maintaining the data needed, and completing and reviewing the collection of information. Send comments regarding this burden estimate or any other aspect of this collection of information, including suggestions for reducing this burden, to Washington Headquarters Services, Directorate for Information Operations and Reports, 1215 Jefferson Davis Highway, Suite 1204, Arlington, VA 22202-4302, and to the Office of Management and Budget, Paperwork Reduction Project (0704-0188), Washington, DC 20503.

\begin{tabular}{|l|l|l}
\hline 1. AGENCY USE ONLY (Leave blank) & $\begin{array}{c}\text { 2. REPORT DATE } \\
\text { July } 2003\end{array}$ & $\begin{array}{r}\text { 3. REPORT TYPE AND DATES COVERED } \\
\text { Technical Memorandum }\end{array}$ \\
\hline
\end{tabular}

\section{TITLE AND SUBTITLE} 5. FUNDING NUMBERS

Test Rig for Evaluating Active Turbine Blade Tip Clearance Control Concepts

6. AUTHOR(S)

WBS-22-708-87-06

Scott B. Lattime, Bruce M. Steinetz, and Malcolm G. Robbie

7. PERFORMING ORGANIZATION NAME(S) AND ADDRESS(ES)

National Aeronautics and Space Administration

John H. Glenn Research Center at Lewis Field

Cleveland, Ohio 44135-3191
8. PERFORMING ORGANIZATION REPORT NUMBER

E-14097

\section{SPONSORING/MONITORING AGENCY NAME(S) AND ADDRESS(ES)}

National Aeronautics and Space Administration

Washington, DC 20546-0001
10. SPONSORING/MONITORING AGENCY REPORT NUMBER

NASA TM-2003-212533

AIAA-2003-4700

\section{SUPPLEMENTARY NOTES}

Prepared for the 39th Joint Propulsion Conference and Exhibit cosponsored by AIAA, ASME, SAE, and ASEE, Huntsville, Alabama, July 20-23, 2003. Scott B. Lattime, Ohio Aerospace Institute, Brook Park, Ohio 44142; Bruce M. Steinetz, NASA Glenn Research Center; and Malcolm G. Robbie, Analex Corporation, Brook Park, Ohio 44142. Responsible person, Scott B. Lattime, organization code 5950, 216-433-5953.

Unclassified - Unlimited

Subject Category: 07

Distribution: Nonstandard

Available electronically at http://gltrs.grc.nasa.gov

This publication is available from the NASA Center for AeroSpace Information, 301-621-0390.

\section{ABSTRACT (Maximum 200 words)}

Improved blade tip sealing in the high pressure compressor and high pressure turbine can provide dramatic improvements in specific fuel consumption, time-on-wing, compressor stall margin and engine efficiency as well as increased payload and mission range capabilities of both military and commercial gas turbine engines. The preliminary design of a mechanically actuated active clearance control (ACC) system for turbine blade tip clearance management is presented along with the design of a bench top test rig in which the system is to be evaluated. The ACC system utilizes mechanically actuated seal carrier segments and clearance measurement feedback to provide fast and precise active clearance control throughout engine operation. The purpose of this active clearance control system is to improve upon current case cooling methods. These systems have relatively slow response and do not use clearance measurement, thereby forcing cold build clearances to set the minimum clearances at extreme operating conditions (e.g., takeoff, re-burst) and not allowing cruise clearances to be minimized due to the possibility of throttle transients (e.g., step change in altitude). The active turbine blade tip clearance control system design presented herein will be evaluated to ensure that proper response and positional accuracy is achievable under simulated high-pressure turbine conditions. The test rig will simulate proper seal carrier pressure and temperature loading as well as the magnitudes and rates of blade tip clearance changes of an actual gas turbine engine. The results of these evaluations will be presented in future works.

\section{SUBJECT TERMS}

Blade tip seal; Active clearance control; Test rig design

\section{NUMBER OF PAGES}

29

16. PRICE CODE

\section{SECURITY CLASSIFICATION} OF REPORT

Unclassified

\section{SECURITY CLASSIFICATION OF THIS PAGE \\ Unclassified}

19. SECURITY CLASSIFICATION OF ABSTRACT

Unclassified

20. LIMITATION OF ABSTRACT 